ANA CRISTINA D' ANDRETTA TANAKA

\title{
OBES IDADE
}

E

GRAVIDEZ

Monografia de mestrado apresentada à Faculdade de Saūde Püblica da Univer sidade de São Paulo- Departamento de Saūde Materno-Infantil, para obtençāo do Título de Mestre em Saúde Püblica.

Orientador:

Prof. Pedro Augusto Marcondes de Almeida

\section{SÃO PAULO}

$-1980 .-$ 


\section{Ao meu esposo, minha mãe e minhas filhas, \\ por terem dado sentido à minha vida}

A memória do grande mestre e ami go Prof. Cyro Ciari Junior, pelo grande incentivo, apoio e confiança . 
AGRADEC IMENTOS 
Os agradecimentos que gostaria de poder fazer são inúmeros e perdoem as pessoas que por um lapso possa omitir. Porém aqui mencionarei apenas as que tiveram diretamente ligadas a este trabalho.

Ao Conselho Nacional de Desenvolvimento Científico e Tecno lögico $\left(\mathrm{CNP}_{q}\right)$, pela bolsa de estudos, com a qual nos possibilitou a realização deste trabalho.

Ao meu orientador, Professor Pedro Augusto Marcondes de A1 meida, pelo incentivo, apoio e orientação.

Ao Professor Arnaldo Augusto Franco de Siqueira, pelo incan sável apoio, orientação e discussão no decorrer deste estudo.

A Professora Augusta Thereza de Alvarenga, pela sua colaboraçāo na classificação sóció-econômica deste trabalho . 
A Marly Lipe, pela sua valiosa ajuda na coleta dos dados.

A Dinorah dos Santos, pela sua disposição e ajuda nos trabą lhos de datilografia.

A Redenil Alves de Carvalho, pelos trabalhos preliminares de datilografia.

A Senhora Aurene Pimenta, pelos serviços de Xerox das referências bibliogrāficas deste trabalho.

A Senhora Maria Cecilia Gonzaga Ferreira, pela revisão bibliogräfica.

Ao Professor Arthur Boorne,pela revisão do resumo em Inglês.

E principalmente às gestantes do serviço de Pré-Natal do Centro de Saúde Geraldo de Paula Souza, pela sua colaboração e paciência permitindo, com isto, a realização deste traba 1ho. 
TND ICE 
RESUMO

SUMMARY

1. IntRoDUCAO $\ldots \ldots \ldots \ldots \ldots \ldots \ldots \ldots \ldots \ldots \ldots \ldots \ldots$

2. OBJETIVOS $\ldots \ldots \ldots \ldots \ldots \ldots \ldots \ldots \ldots \ldots \ldots \ldots \ldots \ldots$

3. MATERIAL E METODO ................... 16

4. RESUltados E DISCUSSÃO

4.1. Caracteristicas gerais das gestantes estu

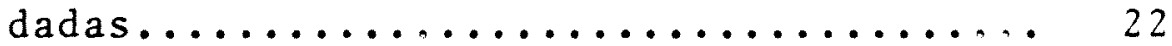

4.2. Estudo do recém-nascido ........... 37

4.3. Consideraçōes gerais ............. 56

5. CONCLUSOES .......................... 58

6. REFERENCIAS BIBLIOGRAFICAS $\ldots \ldots \ldots \ldots \ldots \ldots 60 . \ldots . \ldots$ 
RESUMO

SUMMARY 
Com a finalidade de reconhecer algumas características da evolução da gravidez, em mulheres obesas, e su as repercussões sobre o concepto, foram estudados dois grupos de gestantes, sendo um de grāvidas normais e outro de obesas. Foram selecionadas as seguintes variäveis para este trabalho: status sócio-econômico familiar, idade, altura, perímetro bra quial, peso habitual, número de gestações anteriores, paridade materna, ganho de peso durante a gestação, idade gestacional, intercorrências durante a gestação, peso ao nascer e ví talidade do recëm-nascido. Os resultados encontrados permit ram concluir que as gestantes obesas são diferentes das norma is e apresentam uma maior incidência de complicações obstétri cas. Os recém-nascidos, filhos de obesas registram um indice maior de mortalidade, principalmente no periodo perinatal. Houve maior incidência de prematuridade e de fetos macrossômi cos, sendo, portanto, a curva de distribuição de peso ao nas cer, diferente da dos recém-nascidos das gestantes normais. A média de peso das crianças das gestantes obesas, ao nascer, é superior à das normais. Este trabalho ainda permitiu con- 
cluir que, toda vez que a gestante obesa sofre restrição al $\underline{i}$ mentar, com ganho de peso inadequado, o crescimento intra-ute rino é afetado; portanto, não seria a gravidez a melhor época para a obesa perder peso, mas, ao contrário, ela deveria receber uma orientação alimentar adequada. Conclui-se que a obesidade $\bar{e}$ um fator de aumento do risco gravidico, que po de afetar tanto a mãe como o concepto. 
This study has been carried out with the purpose of discovering some of the characteristics of pregnancy development in obese women and their effect on the newborn. Two groups of pregnant women were studied, one of them of normal pregnant and the other of obese women. The following variables were selected for the study: the socioeconomic sta tus of the family, maternal age, height, arm circumference, pre-pregnancy weight, total number of pregnancies, parity, weight gain during pregnancy, obstetric complications, newborn weight, and fetal vitality. The results showed that the obese mothers were different from the normal ones and that they had a larger incidence of obstetric complications . The children of obese mothers had a higher mortality rate principally in the perinatal period. There was also a higher rate of prematurity and a higher proportion of overweight babies. As a result the distribution curve of the weight of the newborn children of obese mothers was different from that of the children of normal mothers. The average newborn weight of the children of obese pregnancies was higher 
cluir que, toda vez que a gestante obesa sofre restrição al 1 mentar, com ganho de peso inadequado, o crescimento intra-ute rino ê afetado; portanto, não seria a gravidez a melhor época para a obesa perder peso, mas, ao contrário, ela deveria receber uma orientação alimentar adequada. Conclui-se que a obesidade é um fator de aumento do risco gravídico, que pode afetar tanto a mãe como o concepto. 
This study has been carried out with the purpose of discovering some of the characteristics of pregnancy development in obese women and their effect on the newborn. Two groups of pregnant women were studied, one of them of normal pregnant and the other of obese women. The following variables were selected for the study: the socioeconomic sta tus of the family, maternal age, height, arm circumference, pre-pregnancy weight, total number of pregnancies, parity, weight gain during pregnancy, obstetric complications, newborn weight, and fetal vitality. The results showed that the obese mothers were different from the normal ones and that they had a larger incidence of obstetric complications. The children of obese mothers had a higher mortality rate principally in the perinatal period. There was also a higher rate of prematurity and a higher proportion of overweight babies. As a result the distribution curve of the weight of the newborn children of obese mothers was different from that of the children of normal mothers. The average newborn weight of the children of obese pregnancies was higher 
than the normal. This study led to the conclusion that whenever the subject suffered a reduction in food intake, with resultant insufficient weight-gain, intrauterine growth was affected. It was concluded that pregnancy was not the best time for the obese mother to lose weight; for this reason it is important that she receive adequate guidance with regard to diet. This study demonstrates that obesity is a factor contributing to high-risk pregnancy which can affect both mother and child. 
1. INTRODUÇÃO 
Toda enfermidade transmissivel ou não, que afeta uma parcela significativa de uma população, com repercussão sobre a saúde coletiva, se constitui um problema de saūde púb1ica.

Considerando-se esta afirmativa como ver dadeira, a obesidade se apresenta como um problema de Saüde Pública no mundo de hoje.

Vários países desenvolvidos apresentam a umentos consideráveis na prevalênciada obesidade, o que tem levado alguns deles, como por exemplo, os Estados Unidos e alguns países europeus, a considerä-1a como um dos problemas mais preocupantes de Saüde Pública, na atualidade $2,16,51$. A prevalênciada obesidade, nos Estados Unidos, na população adulta está em torno de $25 \%$ a $45 \% 48$.

o Brasil, apesar de ser um país em desen volvimento, apresenta peculiarmente regiões com problemas de saúde cujas características retratam realidades sócio-eco nômicas diferentes. O exemplo típico deste fato e a região metropolitana de São Paulo que, pelas características de de 
senvolvimento econômico, apresenta tanto doenças degeneratí vas e metabōlicas, que são mais frequentes em paỉses desenvolvidos, quanto enfermidades infecto-contagiosas e desnutrí ção, mais comuns nos países em desenvolvimento.

Assim, a obesidade, que nos ültimos anos vem ganhando vulto nos países desenvolvidos, começa a atingir uma parcela cada vez maior de nossa população e, com is to, provoca uma preocupação crescente e uma necessidade de melhor atenção por parte do pessoal especializado em Saúde Püb1ica.

A obesidade é uma desordem, ou doença metabólica, que se caracteriza por um aumento de peso corporal em relaçāo à média de peso para a altura ${ }^{13,17}$, ou ainda, po de ser definida como um excesso de tecido adiposo no organis mo 2,13 . Alguns autores consideram como pessoa obesa toda quela que apresenta um aumento de peso de $20 \%$ em relação ao peso padrão para a altura $8,12,16,17,42,46$. Outros consideram que a mulher é obesa quando tiver um peso acima de $90 \mathrm{Kg}$. $18,28,30,33,47$. Para EDWARDS ${ }^{17}$, quando um indivíduo tiver um peso acima de $50 \%$ do recomendado para sua altura ele é "mací çamente" obeso.

SIQUEIRA e $\operatorname{cols}^{39}$ elaboraram curvas para di agnóstico de estado nutricional materno e consideraram mulhe res obesas aquelas que tem seu peso acima do limite superior destas.

Sendo de etiologia multi-causal, a obesidade sofre influência de fatores orgânicos, psíquicos e/ ou sociais ${ }^{24}$, que podem atuar isoladamente ou em conjunto, so bre o individuo. Fatores genéticos associados com fatores ambientais, tais como maior disponibilidade de alimentos in dustrializados, e vida sedentáría facilitam o desencadeamen- 
to da obesidade. Alguns autores afirmam que fatores sociais -econômicos-culturais e ambientais exercem ação sobre a in gestão excessiva de alimentos e, com isto, provocam no indivíduo um elevado aumento de peso ${ }^{2,24}$. Resumindo, pode- se dizer que a obesidade resulta de um excesso relativo de in gestão calórica para o gasto energético necessário de um da do organismo, levando, com isto, a um aumento na sintese de gordura ou a uma diminuição da mobilização da mesma.

Numa tentativa de classificar todo e qual quer tipo de obesidade, BRAY e $\operatorname{cols}^{7}$ fizeram um quadro sinótico, a fim de fornecer uma sistematização que permita um me lhor diagnóstico desta desordem ou doença metabólica,

Quadro 1 . 


\section{DIAGNOSTICO ANATOMICO}

\section{Hipercelular}

Com aumento no número de adipócitos e grau variado de ala gamento da célula, começando precocemente na infância. Normocelular

Com aumento de tamanho e não do número de adipócitos, começañ do geralmente na idade adulta ou durante a gravidez.

\section{DIAGNOSTICO ETIOLOGICO}

\section{Endócrina}

Excesso de insulina ou de hormônios adrenocorticais. Associada com outras desordens endócrinas como:

- diabetes mellitus, não insulino-dependente

- disfunção ovariana

- disfunção tireoidiana

- doença de Cushing

\section{Hipota1âmica}

Genética

- sindromes raras, associadas com obesidade

- obesidade familiar

Obesidade de origem indeterminada

FONTE: BRAY,C. et al - Evaluation of the obese natient. JAMA, 235: $1487 / 91,1976$. 
De acordo com este quadro de classificação de obesidade, o fator anatômico estā centrado, essencialmente, nas características anátomo-funcionais das células adiposas e, em menor escala, em sintomas e sinais clínicos. Assim, no tipo hipercelular o aumento do número de células é acompanhado de um aumento variāvel de volume e de uma dis função metabōlica discreta, enquanto que no tipo normocelular a principal característica è o aumento do tamanho das células, que acumulam lípides e são freqüentemente acompanhạ das de doenças metabōlicas, como diabetes mellitus não insulino-dependente, hiperlipemia ou hipertensão arterial ${ }^{7} 0$ diagnóstico laboratorialdesses dois tipos é bastante comple xo, pois implicaria na necessidade de medida dos lipides in tra-adipócitos e do cālculo do tecido adiposo corpóreo total, como referem KATZEN e MAHLER 22 .

O diagnöstico clínico è feito essencialmen te levando em conta a época do início da sintomatologia, que é mais precoce na hipercelular, e o tipo de distribuição de tecido adiposo no organismo, que é uniforme no hipercelular e mais concentrado no tronco no tipo normocelular, segundo BRAY $^{7}$.

Dentre os fatores etiológicos de obesidade, a causa mais importante é a endócrina, por ser esta essencialmente uma disfunção metabólica. O excesso de insulina pode ser devido à resistência apresentada pelas células do individuo obeso à açāo insulínica, acarretando, assim, um aumento por mecanismo de compensação desta secreção pelas ilho tas do pâncreas ${ }^{22}$. Ainda segundo KATZEN e MAHLER ${ }^{22}$, is to po derá acarretar um desequilíbrio no metabolismo de glicose, dependendo da maior ou menor ação de compensação pancreática 
à resistência tecidual. Contudo, parece clara a relação en tre a obesidade e o metabolismo dos hidratos de carbono. Como se sube, o excesso de ingestão calórica leva a um consumo maior de insulina que, por vezes, não é suficiente, fa zendo com que os carmhidratos se fixem no tecido adiposo, onde são convertidos em gordura 28 .

A obesidade familiar é a causa mais impor tante entre os fatores genéticos, pois alēm da tendência familiar à obesidade, hả a influência do meio ambiente e de hábitos alimentares, concorrendo para um desequilíbrio de in gestão calórica ${ }^{2,7,12,31}$. GAIN e CLARK ${ }^{21}$ explicam a tendēn cia familiar dizendo que, quando o pai e a mãe são obesos, o filho tende à obesidade; por outro lado, quando ambos os pais são delgados, seus filhos tendem a ser delgados também. Mostram, ainda, que quando a mãe é obesa, o recẻm-nascido tem uma maior tendência à obesidade, mais do que quando a mãe $\vec{e}$ delgada ou normal, independente da constitưição do marido, embora este tambēm tenha importância na tendência à obesidade de sua prole. O gräfico I, abaixo ilustra esta explica ção. 
GRAFICO I - RELAÇÃO ENTRE A MEDIA Z DE"SCORE"PARA PREGA

CUTÃNEA DE RECEM-NASCIDO E TIPO DE GORDURA DOS PAIS

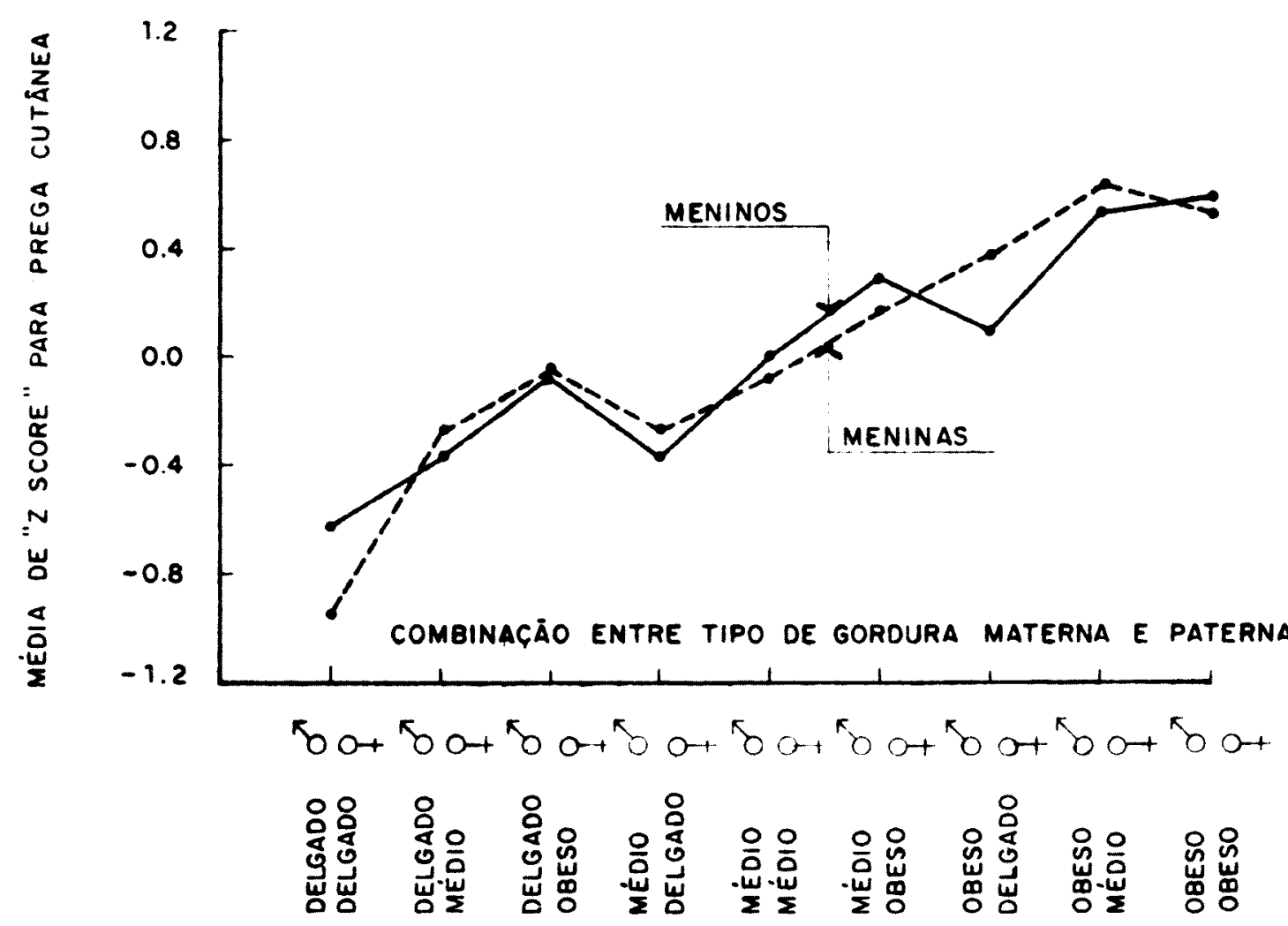

FONTE: GAIN,S.M。 \& CLARK,D.C.- Trends in fatness and the origins of obesity. Pediatrics, 57: 450,1976.

Mas, apesar de todos os esforços para a elucidação etiológica da obesidade, um grande número de obe sos são classificados na categoria de origem indeterminada, por não ser possível identificar a causa específica para es ta disfunção metabōlica ${ }^{7}$. Contudo, a não identificação de fator etiológico não implica em uma não atuação sobre a obe sidade, com o objetivo de minimizar e/ou controlar este pro blema, pois quanto mais precoce for a atuação, no sentido de corrigir e/ou controlar esta disfunção, menor será o ris co de agravos à saúde, a que o obeso estā exposto. 
ALBRINK $^{2}$ e ROBSON ${ }^{34}$, entre outros auto res, relatam que a obesidade é um fator de aumento de morb $\underline{i}$ dade no ser humano, com maior prevaléncia de doenças, principalmente cardiovasculares, arteroscleróticas, hemodinâmicas e outras, tais como as que causam problemas respiratór os, colecistites, orteoartrites, veias varicosas, hérnias ventrais e diafragmáticas, etc, além do diabetes, que pare ce ter uma forte associação com a obesidade.

Os problemas cardiovasculares e os hemodinâmicos são decorrentes de um aumento do volume sanguíneo circulante, que se deve a uma rede vascular adicional, por causa do excesso de tecido adiposo, acarretando, por sua vez, repercussões sobre o sistema cardiovascular,

A arterioesclerose ocorre pelo acúmulo subendotelial do colesterol, triglicérides e fosfolípedes, ocluindo assim, parcial ou totalmente, a luz dos vasos, Es te acúmulo resulta do excesso dessas substâncias circulando no organismo, em razão de obesidade e da elevada ingestão de hidratos de carbono, acarretando, com isto, um desequili brio no metabolismo destes ültimos. A arterioesclerose é, hoje em dia, uma das enfermidades degenerativas de mais al ta prevalència.

Um ūltimo ponto a ser levado em considera ção é o problema psicológico associado à obesidade. Segundo CORMILLOT e cols ${ }^{12}$ e KIELL ${ }^{24}$, os fatores psicolögicos estão relacionados tanto com o desencadeamento como com o tratamen to da obesidade. Quanto ao primeiro, ele parece favorecer $\underline{u}$ ma conduta impulsiva frente à comida representando esta um mecanismo de defesa ou de compensação a ansiedades , "stress", 
angüstia, ete.. Quanto no tratamento, a correlação entre pro blemas psicológicos e obesidade se constitui numa base impor tante de tratamento.

Pelo que foi visto, at agora, a obesidade é um fator de risco, pois expõe o individuo a uma maior mortalidade e morbidade.

Como se sabe, a gestaçāo, por si sō, leva a mulher a um risco gravídico que, quando associado a outros fatores de risco, como, por exemplo, a obesidade, podem predispor tanto a gestante quanto o concepto a um aumento na mor bi-mortalidade materno-fetal.

CORMILLOT e cols ${ }^{12}$ referem autores que re latam ser a prevalência de obesidade, na mulher grávida, da ordem de 20 a $45 \%$ e que a gestação pode atuar como desencade ante da obesidade, ou como agravante desta, quando for pré existente.

A grande maioria dos autores de trabalhos sobre o assunto afirmam que a associação obesidade-gravidez aumenta a incidência de complicaçōes maternas, levando mãe e filho a um alto risco.

MAEDER e $\operatorname{cols}^{26}$ fizeram um estudo de mortalidade materna, em Minnesota, durante um período de 10 a nos e verificaram que, entre as gestantes que faleceram, 12: eram obesas, isto é, pesavam mais de $90 \mathrm{Kg}$, sendo a principal causa de morte, neste grupo, a embolia pulmonar e a segunda as hemorragias, principalmente pós-parto. Para este mesmo autor, se o critério para o diagnóstico da obesidade na gravidez fosse $80 \mathrm{~kg}$ ao invés de $90 \mathrm{~kg}$, ter-se-ia uma incidência de obesidade de $18 \%$ entre as gestantes falecidas. 
A principal causa de morbidade materna entre grávidas obesas sĩo as doenças hipertensivas, predomi nantemente a toxemia gravídica. PETRY ${ }^{33}$ encontrou uma in cidência de $35.5^{\circ}$ de doencas hipertensivas entre as gestantes obesas contra $14,8^{\circ}$ no total das gestantes, que foram a tendidas no hospital onde ele realizou seu estudo, no Ken tucky.

FISCHER e FREY ${ }^{18}$ mostram em seu estudo $\underline{u}$ ma incidência duas vezes maior de toxemia no grupo de ges tantes obesas que no grupo controle. TRACY e MILLER ${ }^{7}$ rela tam que as grávidas obesas têm uma incidência 7 vezes maior de toxemia que as normais. EDWARDS e cols ${ }^{17}$, ODELL e MENGERT $^{j 0}$, MATHEWS e DER BRUCKE ${ }^{28}$ também encontram uma maior incidência de toxemia e desordens hipertensivas nas gestantes obesas. Parece ser, portanto, a obesidade um fator pre disponente a doenças hipertensivas de um modo geral.

Em relaçāo ao feto, as doenças hipertensivas são uma das causas de baixo peso ao nascer, e de mor talidade perinatal. E o que mostra o estudo feito por BUTLER e BONHAM ${ }^{9}$ na Inglaterra, Escócia e País de Gales, em 1968, em que se encontrou que $8:$ das mortes perinatais ocor reram em filhos de toxêmicas.

Outra complicaçāo frequente em obesas grạ vidas é a hemorragia, principalmente pós-parto $12,28,30$.

No que respeita a gestação, pelo fato da mesma ser diabetogênica, o diabetes quando associado a ela, apresenta uma maior incidência no grupo de gestantes obesas, como assinalam alguns autores $17,28,47$, O aumento desta incidência, verificada por eles, é da ordem de $3,4 \% 28$ a $10,4 \%$ 17,47 
A literatura ainda menciona outras complicações maternas, tais como pielonefrites, tromboembolis mo, lesões ou infecções de cicatriz cirúrgica, que tem sua incidência aumentada em grávidas obesas 12,17,34,48

Para alguns autores, as gestantes obesas têm uma incidência maior de fetos em apresentação pêlvica, ou gestações mültiplas $28,30,47$.

No período gestacional, a mulher grävida deve ganhar de 9 a $12 \mathrm{Kg}$, porém, muitas vezes, por problemas culturais, comportamentais, ambientais e/ou sociais, a gestante apresenta um ganho de peso inadequado, tanto para mais como para menos em relação aos 1 imites recomendados.

KAWAKAMI e $\operatorname{cols}^{23}$, em seu estudo, verif $\underline{\mathbf{i}}$ caram que quando as gestantes ganhavam menos de $7 \mathrm{Kg}$, durante a gravidez, a média de peso dos conceptos ao nascer esta va abaixo de $2.700 \mathrm{~g}$ e, se ganhassem menos de $5 \mathrm{Kg}$, esta médi a caía para menos de $2.500 \mathrm{~g}$. Por outro 1 ado, quando as grạ vidas tinham um aumento de peso acima de $12 \mathrm{Kg}$, praticamente não havia correlação entre o ganho de peso materno e o peso fetal, sendo o peso do recém-nascido normal.

SPRINGER e $\operatorname{cols}^{44}$ mostram, em seu estudo, a relação existente entre o peso pré-gestacional, e o peso e a altura do recém-nascido e também a correlação positiva entre o ganho de peso materno durante a gravidez e peso, altura e circunferência craniana do concepto.

SIMPSON e cols ${ }^{38}$ fizeram uma extensa revi são em prontuārios de mulheres grāvidas, com gestação a termo, registrados durante um período de 20 anos num Hospital militar no Texas-USA, e verificaram a associação existente 
A literatura ainda menciona outras complicaçōes maternas, tais como pielonefrites, tromboembolis mo, lesōes ou infecções de cicatriz cirúrgica, que tem sua incidência aumentada em grávidas obesas 12,17,34,48.

Para alguns autores, as gestantes obesas têm uma incidência maior de fetos em apresentação pélvica, ou gestações mültiplas $28,30,47$.

No período gestacional, a mulher grävida deve ganhar de 9 a $12 \mathrm{Kg}$, porëm, muitas vezes, por problemas culturais, comportamentais, ambientais e/ou sociais, a gestante apresenta um ganho de peso inadequado, tanto para mais como para menos em relação aos limites recomendados.

KAWAKAMI e $\operatorname{cols}^{23}$, em seu estudo, verif $\underline{\mathbf{i}}$ caram que quando as gestantes ganhavam menos de $7 \mathrm{Kg}$, durante a gravidez, a média de peso dos conceptos ao nascer esta va abaixo de $2.700 \mathrm{~g}$ e, se ganhassem menos de $5 \mathrm{Kg}$, esta mëd $\underline{i}$ a caía para menos de $2,500 \mathrm{~g}$. Por outro 1 ado, quando as grạ vidas tinham um aumento de peso acima de $12 \mathrm{Kg}$, praticamente não havia correlação entre o ganho de peso materno e o peso fetal, sendo o peso do recém-nascido normal.

SPRINGER e $\operatorname{cols} \mathrm{s}^{44}$ mostram, em seu estudo, a relação existente entre o peso pré-gestacional, e o peso e a altura do recém-nascido e também a correlação positiva entre o ganho de peso materno durante a gravidez e peso, altura e circunferência craniana do concepto.

$$
\text { SIMPSON e } \operatorname{cols}{ }^{38} \text { fizeram uma extensa revi }
$$

são em prontuārios de mulheres grāvidas, com gestação a termo, registrados durante um período de 20 anos num Hospital militar no Texas-USA, e verificaram a associação existente 
entre peso pré-gestacional, ganho de peso durante a gravidez e o peso do recém-nascido. Assim, verificaram que quan to maior era o peso pré-gestacional maior era o peso do re cém-nascido; a mesma relação direta se observou entre o ga nho de peso durante a gravidez e o peso do recém-nascido. Essas relaçōes foram diretas até um determinado limite. As sim, para as gestantes que tinham um peso prë-gestacional a1 to (maior de $73 \mathrm{Kg}$ ), o peso do recém-nascido aproximou- se ao das gestantes com menos de $73 \mathrm{Kg}$. Este fato se deveu pro vavelmente à restrição alimentar feita às grávidas com peso pré-gestacional acima de $73 \mathrm{Kg}$, pois ocorreu uma maior incidência de perda de peso durante a gestação neste grupo. Eles concluem que os recém-nascidos de mulheres que têr ma ior peso pré-gestacional e um maior ganho de peso durante a gestação, pesam mais do que aqueles que tến um maior peso pré-gestacional e pequeno ganho de peso durante a gravidez. Logo, durante o período gestacional a grávida não deverá de $\underline{i}$ xar de ganhar peso, pois isto ira repercutir no peso do feto.

SIMPSON e cols ${ }^{38}$ encontram, resultados se melhantes ao de KAWAKAMI e $\operatorname{col}^{23}$, ou seja ganhar pouco peso durante a gravidez afeta ao peso do recém-nascido, enquanto que ganhar muito peso não afeta o peso do concepto; logo, o que é restritivo ao crescimento do feto é o ganho de peso $\underline{i}$ nadequado durante a gestação.

Como se vê, o conccpto é afetado por estados mórbidos maternos ou por restrições alimentares que a mãe venha a sofrer independente do seu estado nutricional. Contudo, observa-se que, de uma maneira geral, a gestante o besa sofre restrição alimentar durante o período gestacional 
por recomendação médica. Alguns obstetras acham que o re cēm-nascido não é afetado por regime alimentar, não sendo contra-indicado que a gestante obesa perca peso neste perío do. O importante, para eles, $\vec{e}$ que a obesa não venha a ga nhar ainda mais peso durante este periodo.

Além disso, a perda ou falta de ganho de peso pode implicar em catabolismo dos tecidos maternos, pro vocando o desenvolvimento de cetoses, o que poderá comprome ter o desenvolvimento neurológico fetal 17 .

Os recém-nascidos filhos de gestantes obe sas, de um modo geral, são maiores que os filhos de não obesas, porém, não excessivamente maiores $17,40,48$. E importante notar que a incidēncia de baixo peso ao nascer, por re tardo de crescimento intra-uterino, é menor nos filhos de mães obesas, apesar das complicações obstétricas a que este grupo está exposto. Quanto às crianças que ao nascer apre sentam peso acima de $4.000 \mathrm{~g}$, encontrou-se uma incidência significativamente maior entre os filhos de mães obesas do que as de não obesas ${ }^{17,48}$. CORMILlot e cols ${ }^{12}$ e BATISTA $^{6}$, entre outros autores, referem uma morbi-mortalidade maior nas crianças com peso acima de $4000 \mathrm{~g}$.

A tendéncia familiar da obesidade é um fa tor importante no tamanho do feto, pois, pelo que foi visto até agora, os filhos das gestantes obesas são, de um modo ge ral, maiores.

Este aumento de peso do recém-nascido tem sido atribuído a um aumento na adiposidade. UDALL e cols 48 , em estudo feito no Centro médico da Universidade de Arizona com gestantes não diabëticas, verificaram que os filhos de gestantes obesas eram maiores que os das normais e que estes 
recēm-nascidos tinham um aumento no tecido adiposo subcutâneo. Concluíram que o ganho de peso, durante a gestação, está associado com o aumento da obesidade e comprimento do recém-nascido, embora o elcvado peso pré-gestacional se associe à obesidade do concepto, independente do comprimento deste.

$$
\text { WHITELAW }{ }^{50} \text { mostra, em seu trabalho, que }
$$

a obesidade materna (quer aquela pré-gestacional ou o ganho excessivo durante a gravidez) está associada a um aumento de gordura subcutânea do recém-nascido. Segundo este autor, - fato se deve à passagem de ácidos graxos 1 ivres através da placenta, herança de uma taxa metabólica mais baixa, e diminuição da atividade física "in utero" . Afirma, tambëm, que este aumento de gordura subcutânea no recém-nascido, filho de obesa, poderia explicar a tendência de obesidade familiar.

Portanto, quando a gravidez desencadeia a obesidade, ou está associada a esta, leva o binômio māefilho a uma maior vulnerabilidade de adoecer e morrer por complicaçōes tanto obstétricas como clínicas.

Este trabalho visa a conhecer algumas ca racterísticas da evolução da gravidez em mulheres obesas. bem como possíveis influências da obesidade na gravidez, que possam estar afetando o crescimento intra-uterino e a saúde e vitalidade do feto. 
2. OBJETTVOS 
Objetivou-se com este trabalho estudar o binômio obesidade e gravidez, uma vez que esta associação é um fator de risco a que podem estar expostos tanto a mãe quanto o concepto, implicando uma morbi-mortalidade maior. Esta pesquisa visa estudar variäveis ma ternas: status sócio-econômico familiar, idade, número de gestações anteriores, paridade, altura, perímetro braquial, peso habitual, ganho de peso durante a gestação, idade gestacional e intercorrēncias durante a gestaçāo, que possam estar influindo no peso ao nascer, e na vitalidade dos recém-nascidos das gestantes obesas e compará-1as com as das normais, numa tentativa de identificar possiveis fatores que estejam interferindo no resultado da gestação e, conhe cer a prevalênciada obesidade nesta população de gestantes. 
3. MATERIAL E METODO 
Para este estudo foram consideradas as gestantes inscritas no período de $01 / 07 / 77$ a $30 / 10 / 78$ no Serviço de Pré-Natal do "Centro de Saúde Geraldo de Paula Souza da Faculdade de Saúde Pública da USP". Destas gestantes foram selecionadas para um estudo prospectivo 132, que preenchiam os seguintes critérios:

a) haviam comparecido ao Serviço de Pré-Natal para sua primeira consulta até a $25 a$. semana de gestação;

b) não registraram nenhuma patologia pró pria ou associada à gravidez na primeira consulta;

c) não apresentaram gravidez gemelar ;

d) haviam feito consulta de puerpërio.

Estas gestantes foram então divididas em dois grupos sendo um de normal e outro de obesa segundo critērio de classificação.

\section{CRITERIO DE CLASSIFICAÇAO DE GESTANTE NORMAL E OBESA}

Para a classificação das gestantes em obe sas e normais foram utilizadás as "Curvas de ganho de peso" para gestantes de SIQUEIRA e $\operatorname{col}^{39}$. Toda gestante que estava entre - 1 (um) desvio-padrão a + 1 (um) desvio-padrão da curva foi considerada normal, bem como as que estavam abaixo de - 1 desvio-padrāo e que, durante o decorrer da gravidez, 
passassem acima deste limite e ai permanecendo, Assim sen do, este grupo contou com 81 gestantes.

Foram consideradas gestantes obesas as que estavam acima de + l (um) desvio-padrio da "Curva de sa nho de peso" ou que estavam no espaço da curva considerado como normal e, no decorrer da gravidez, passaram para cima do 1 imite +1 (um) desvio-padrão. Ou, ainda, aquelas que os cilaram durante a gravidez, no limite superior da curva, mas que terminaram com seu peso acima do 1 imite definido como normal. Este grupo compreendeu 51 gestantes.

As variáveis que seguem foram consideradas de importância para o presente estudo, sendo, portanto, coletadas e anotadas em ficha padronizada para tal:

\section{a) Dados Pessoais:}

Nome : completo

Idade: em anos completos

Nümero da ficha de pré-natal

Classificação do nível de status sócio-econômico familiar:

de acordo com a classificação de ALVARENGA e cols ${ }^{4}$, que con ta com a combinação estatística das seguintes variações:

ocupação do marido ou responsāvel pela familia, renda mensal por pessoa da familia, escolaridade da gestante e do marido ou companheiro. 


\section{b) Antecedentes Obstëtricos}

Foram anotados todos os dados de importância, que podiam in fluenciar direta ou indiretamente à gestação atual.

\section{c) Dados antropométricos da gestante}

Estatura: era obtida com a régua milimetrada existente na balança antropomëtrica. A gestante assumia a posição ereta sem sapatos e a aproximação era feita até $0,5 \mathrm{~cm}$.

Peso Pré-gestacional: era obtido por informação da gestante.

Peso atual: toda gestante era pesada na mesma balança antro pomëtrica Filizola, com vestido, sem sapatos e sem abrigo ou malha de 1 ã e com aproximação de até 100 gramas.

Perímetro braquial: era medida a circunferência do braço es querdo da gestante na meia distância entre o acrômio e o olécrano, com fita métrica plästica inextensivel, com aproximação de $0,5 \mathrm{~cm}$.

Os dados de peso e perímetro braquial fo ram tomados em todas as consultas de controle pré-natal, sen do os demais apenas na primeira consulta. 
d) Histōria da gravidez atual

Data da ūitima menstruação (DUM)

Evolução da gravidez atual: diagnóstico feito pelo médico prenatalista.

Idade gestacional : cảlculo feito a partir da data da ültí ma menstruação.

Ganho de peso durante a gravidez: cảlculo feito a partir da diferênça entre o peso da ūltima consul ta e o da primeira consulta.

Ganho de peso semanal: cálculo feito a partir da diferença entre o peso da ültima consulta e da primeira consulta, dividido pela diferença entre a idade gestacional da ültí - ma consulta com a primeira consulta.

Ganho de peso semanal $=\frac{P \text {. da ültima cons. }-P_{\circ} \text { da } 1 \text { a. cons }}{\text { idade gest. da ültima consulta - ida }}$ de gestacional da la, consulta

Foi feito este cálculo apenas para as ges tantes que deram a 1 uz a crianças com 37 semanas e mais, e que a ültima consulta tivesse sido realizada até, no mínimo, 4 semanas antes do parto. 
e) Tipo de parto e data do nascimento

f) Vitalidade do recém-nascido

g) Intercorrências do recém-nascido

h) Antropometria do recém-nascido

Peso ao nascer

Este quatro ültimos dados eram obtidos em consulta de puerpério, através de informaçōes que a puerpera trazia do hospital ou por informação pessoal.

Para as variáveis em estudo foram calculadas as médias dos seus diferentes valores e feita anālise estatistica.

Anälise estatistica

Foi feito o teste de Quiquadrado $\left(x^{2}\right)$ e - teste de igualdade de duas médias estatísticas; para tal foi escolhido o método $z$, que é definido pela fórmula :

$$
z=\frac{\bar{x}-\bar{x}_{2}}{\sqrt{\frac{s^{2}}{s_{2}^{2}}+\frac{2}{n_{1}}}}
$$

Para a anälise deste mētodo foi utilizada orientação de SPIEGEL ${ }^{41}$. 
.21

0 nível de significância, tanto para o

teste de $x^{2}$ como o de $z$, foi fixado em $5 \%$ 
4. RESULTADOS E DISCUSSÃO 
4.1. Caracteristicas gerais das gestantes estudadas.

Inicialmente procurou-se verificar se ha via diferenças entre o grupo de gestantes obesas e normais.

\subsubsection{Idade das gestantes}

A média de idade da população de gestantes estudadas é de 27,66 anos; porém, as obesas apresentam uma idade significativamente maior que as normais, como pode ser constatado na tabela 1 .

TABELA 1 - IDADE DAS GESTANTES DOS DOIS GRUPOS EM ESTUDO

\begin{tabular}{l|c|c|c}
\hline GESTANTES & NQ DE CASOS & MEDIA DE IDADE & DESVIO-PADRAO \\
\hline Normais & 81 & 26,8 & 5,6 \\
Obesas & 51 & 29,0 & 6,0 \\
\hline
\end{tabular}

Diferença significativa ao nível de $p<0,01$

Estes dados são semelhantes aos relatados

por PECKHAM e CHRISTIANSON ${ }^{32}$ PRETY $^{33}$ e ODELL e MENGERT ${ }^{30}$, 。 que permite concluir que, de um modo geral, as gestantes obesas apresentam idade maior que as normais.

4.1.2. Status sócio-econômico familiar

O nível de status sócio-econômico famili 
ar das gestantes que frequentam o "Centro de Saūde Geraldo de Paula Souza": foi elaborado por ALVARENGA e $\operatorname{col}^{4}$, que analisaram a relação existente entre escolaridade, ocupação e renda, tanto da grávida como de seu companheiro, possibilitando com isto, uma estratificação em classes sociais.

$$
\text { A tabela } 2 \text { mostra como se comporta a es- }
$$
tratificação social dos dois grupos em estudo, Como se pode observar, as duas populações provêm, predominantemente, das classes média e média baixa. Este fato se deve à localiza ção geogräfica do Centro de Saūde (Jardim América e Vila Madalena), o que favorece um afluxo maior desta classe. Esta distribuição foi um fator limitante de análise, pois imposs $\underline{i}$ bilitou verificar se existe alguma relaça entre o status-só cio-econômico familiar e o estado nutricional das gestantes, no caso especifico, a obesidade.

TABELA 2 - STATUS SOCIO ECONOMICO FAMILIAR DOS DOIS GRUPOS DE GESTANTES EM ESTUDO。

\begin{tabular}{l|r|r|r|r}
\hline & \multicolumn{2}{|c|}{ NORMAIS } & \multicolumn{2}{|c}{ OBESAS } \\
\cline { 2 - 5 } Status & No & $:$ & $\mathrm{N} \odot$ & $\vdots$ \\
\hline 1. Baixa & 6 & 7,4 & 3 & 5,9 \\
2. Média baixa & 47 & 58,0 & 32 & 62,7 \\
3. Média média & 21 & 25,9 & 11 & 21,6 \\
4. Média alta & 6 & 7,5 & 5 & 9,8 \\
5. Alta & 1 & 1,2 & - & - \\
\hline
\end{tabular}


Como se vê, o comportamento dos dois gru pos de gestantes, em relação à classe social, è muito semeThante, pois existe uma grande concentração nos niveis de status 2 e 3 para os 2 grupos de gestantes.

\subsubsection{Nümero de gestações anteriores e paridade.}

A literatura, em geral faz menção tanto à variável nümero de gestaçōes anteriores ${ }^{32}$ como à paridade ${ }^{33}$. Esses autores relatam que as gestantes besas apresentam número de gestações anteriores e/ou paridade maior do que as não obesas. O presente estudo constata a mesma relação, como mostram as tabelas 3 e 4 . Apesar disto, essas diferenças, em número de gestaçōes e paridade, não são significativas; existe, entretanto, uma tendência de as gestantes obesas terem mais gestações e mais filhos que as normais.

TABELA 3 - NOMERO DE GESTAÇOES ANTERIORES DOS DOIS GRUPOS DE GESTANTES EM ESTUDO.

\begin{tabular}{l|c|c|c}
\hline GESTANTES & No DE CASOS * & $\begin{array}{c}\text { MEDIA DE } \\
\text { GESTACCOES }\end{array}$ & DESTIO -PADRAO \\
\hline Normais & 59 & 1,9 & 1,2 \\
Obesas & 39 & 2,4 & 1,6 \\
\hline
\end{tabular}

Diferença não significativa ao nível de $5 \%$

* Excluídas as nrimigestas. 
TABELA 4 - PARIDADE DOS DOIS GRUPOS DE GESTANTES EM ESTUDO

\begin{tabular}{l|c|c|c}
\hline GESTANTES & NO DE CASOS* $^{*}$ MEDIA DE PARIDADE & DESVIO-PADRAO \\
\hline Normais & 55 & 1,4 & 0,9 \\
Obesas & 36 & 1,8 & 1,1 \\
\hline
\end{tabular}

Diferença não significativa ao nível de 5\%

* Excluídas as nuliparas.

DIDDLE $^{15}$ diz que a obesidade em mulheres grávidas não é apenas efeito da gestação, mas de um processo que se inicia desde a infância ou adolescência, alēm de a mulher, comumente, aumentar de peso a cada gestação que ocor re. Outro fato é o aumento de peso em decorrência da idade. Portanto, a obesidade pode ser uma consequência da idade e de paridade maior. Como se pode observar nas tabelas, até agora apresentadas, os grupos das gestantes obesas apresentam idade e paridade mais elevadas que o grupo das normais. Cabe, ainda, mencinnar que nos dois grupos, o número de gestações anteriores é maior que a paridade, ocorrendo, portanto, perdas fetais anteriores, da ordem de $1: 4$ gestações nas grávidas normais e $1: 3,5$ gestaçōes para as obesas.

\subsubsection{Estatura e peso prë-gestaciona1}

E interessante notar que não houve diferen 
ça na média de estatura dos dois grupos de grávidas, sendo esta de 1,56m. Este fato também ocorreu no estudo de PECKHAM e CHRISTIANSON ${ }^{32}$, com a diferença de que a mëdia de estatura, em sua população de grávidas normais e obesas, foi de $1,62 \mathrm{~m}$. Esta diferença entre a estatura das gestantes des te estudo e o de PECKHAM e CHRISTIANSON ${ }^{32}$ não se deve provavelmente à herança genética, mas possivelmente em consequência de problemas nutricionais decorrentes de uma alimentação inadequada, visto que, em nosso País, um dos nrincipais problemas de Saúde Püblica ainda $\vec{e}$ a desnutrição?

$$
\text { Aliäs, TAKAHASHI }{ }^{4} \text { verificou, no Japão, }
$$

um aumento substancial da estatura de crianças pré-adolescen tes, num prazo de 60 anos, mostrando com isto que o que var $\underline{i}$ ou no Japão, neste tempo, não foi o fator genético, mas uma melhor condição nutricional. E provável que esta diferença encontrada entre as mulheres deste estudo e as de PECKHAM e CHRISTIANSON ${ }^{32}$ se deva a fatores ambientais.

$$
\text { Quanto ao peso pré-gestacional, para }
$$

PECKHAM e CHRISTIANSON ${ }^{32}$ gestantes obesas apresentavam peso maior que as normais. Na tabela 5 , pode-se verificar este mesmo fato para o presente estudo, sendo esta diferença esta tisticamente significativa: acima de $\alpha<0,20 \%$, 
TABELA 5 - PESO PRE-GESTACIONAL DOS DOIS GRUPOS DE GESTANTES EM ESTUDO.

\begin{tabular}{l|c|c|c}
\hline GESTANTES & $N$ DE CASOS & PESO HABITUAL MEDIO & DESVIO-PADRAO \\
\hline Normais & $80 *$ & 52,9 & 5,5 \\
Obesas & $49 * *$ & 66,4 & 10,8 \\
\hline
\end{tabular}

* 1 (um) peso prë-gestacional ignorado

** 2 (dois) pesos pré-gestacionais ignorados

Diferença significativa ao nível de $p<0,002$

Como se vê, o grupo de gestantes obesas apresenta uma maior média de peso prë-gestacional jä no período pré-gravídico, iniciando, portanto, a gravidez com pe so maior.

\subsubsection{Perímetro Braquial}

A fim de se constatar se o perímetro braquial poderia servir como uma medida antropométrica para o diagnóstico de obesidade, pois devido à facilidade de sua ob tençāo tornou-se uma técnica viável para estudos populacio nais, foi feita esta mensuração nas gestantes deste estudo e constatou-se que as grávidas normais têm valores menores 
que as obesas. Lsta diferença é estatisticamente significante ao nivel de $0,20^{\circ}$ (tabela 6 )

TABELA 6 - PERTMETRO BRAQUIAL DOS DOIS GRUPOS DE GESTANTES EM ESTUDO

\begin{tabular}{l|c|c|c}
\hline GESTANTES & No DE CASOS & $\begin{array}{c}\text { MEdIA DO PERTMETRO } \\
\text { BRAQUIAL }\end{array}$ & DESVIO-PADRAO \\
\hline Normais & 81 & 27,5 & 1,9 \\
Obesas & 51 & 52,0 & 2,6 \\
\hline
\end{tabular}

Diferença significativa para $p<0,002$

Para as normais, a média do perímetro bra quial se relaciona ao percentil 50 de tabela de FRISANCHO ${ }^{19}$, enquanto que as obesas ao percentil 85. Assim sendo, esta medida é de grande valia no diagnóstico de obesidade, pois, associada ao peso da gestante, pode identificar, com boa mar gem de segurança, grāvidas normais e obesas.

4.1.6. Intercorrências durante o processo gravídico.

A maior preocupação dos obstetras são as intercorrências, que podem advir durante a gravidez, princi palmente quando fatores de risco orgânico se associam à gra videz. ALMEIDA e cols $\mathrm{s}^{3}$, DELASCIO e ALMEIDA ${ }^{14}$, MAEDER e cols 26 , entre outros, classificam a obesidade como um fator de 
alto risco.

Vārios outros autores mostram que ocorre uma incidencia muito maior de patologias próprias e associa das ao ciclo gravido-puerperal em gestantes obesas. E tam bém há uma maior incidência de partos distócicos neste gru po de grāvidas $17,18,28,30,47$.

No presente estudo, tal fato foi observa do. Porém, pelo critério rigoroso de seleção do grupo, no qual toda a gestante quer obesa quer normal, que apresentas se patologia pröpria ou associada à gravidez na primeira consulta deveria ser excluída do estudo, a incidência de pa tologia foi pequena, como pode ser observado na tabela 7 .

TABELA ? - INCIDENCIA DE PATOLOGIAS NOS DOIS GRUPOS DE GESTANTES EM ESTUDO.

\begin{tabular}{|c|c|c|c|c|}
\hline \multirow[b]{2}{*}{ PATOLOGIA } & \multicolumn{2}{|c|}{ NORMAIS } & \multicolumn{2}{|c|}{ OBESAS } \\
\hline & $\mathrm{N}^{8}$ & $\therefore$ & $N^{9}$ & $:$ \\
\hline Diabetes & 1 & 1,2 & - & - \\
\hline Anemia & 1 & 1,2 & - & - \\
\hline $\begin{array}{l}\text { Doenças hipertens } \\
\text { vas }\end{array}$ & - & - & 4 & 7,8 \\
\hline Infecção Urināria & - & - & 2 & 3,9 \\
\hline Ausência de pato- & & & & \\
\hline $\operatorname{logia}$ & 79 & 97,5 & 45 & 88,34 \\
\hline
\end{tabular}


Como esta tabela mostra, houve apenas 1

caso de diabetes declarado entre as gestantes normais. Es ta gestante, porém, tinha história de feto anterior macros sómico e seu peso, no decurso da gravidez, sempre esteve tangenciando o limite superior da Curva de SIQUEIRA e col 39

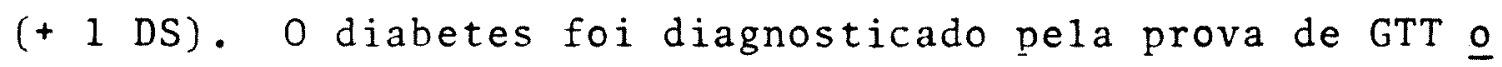
ral. E preciso ressaltar que as gestantes obesas, mesmo com história de crianças que nasceram com peso acima de $4000 \mathrm{~g}$, não fizeram prova de GTT oral para diagnóstico de dí abetes; portanto, não fica afastada a hipótese de coexistên cia desta patologia nas grávidas obesas, uma vez que esta prova não foi feita sistematicamente em todas as gestantes obesas deste estudo.

A hipertensão arterial, diagnosticada na gestação, pode ser devida a toxemia ou a sindromes hipertensivas de outras causas. As gestantes obesas, que apresenta ram hipertensão $(7,8 \%)$ a tiveram no último trimestre da gra videz; portanto, esta pode ser decorrente de uma sindrome toxêmica não diagnosticada.

EDWARDS e $\operatorname{cols}^{17}$ fazem uma comparação em värios estudos com obesas e as incidências das complicações obstétricas apresentadas entre eles. Com o intuito de com parar os dados deste trabalho com os de outros autores, fo ram associados os resultados obtidos aos da tabela de EDWA DS e $\operatorname{cols}^{1 j}$, (tabela 8 ). 
TABELA 8 - INCIDENCIA DE COMPLICAÇOES OBSTETRICAS EM PACIEN TES OBESAS. COMPARAÇÃO COM OUTROS TRABALHOS.

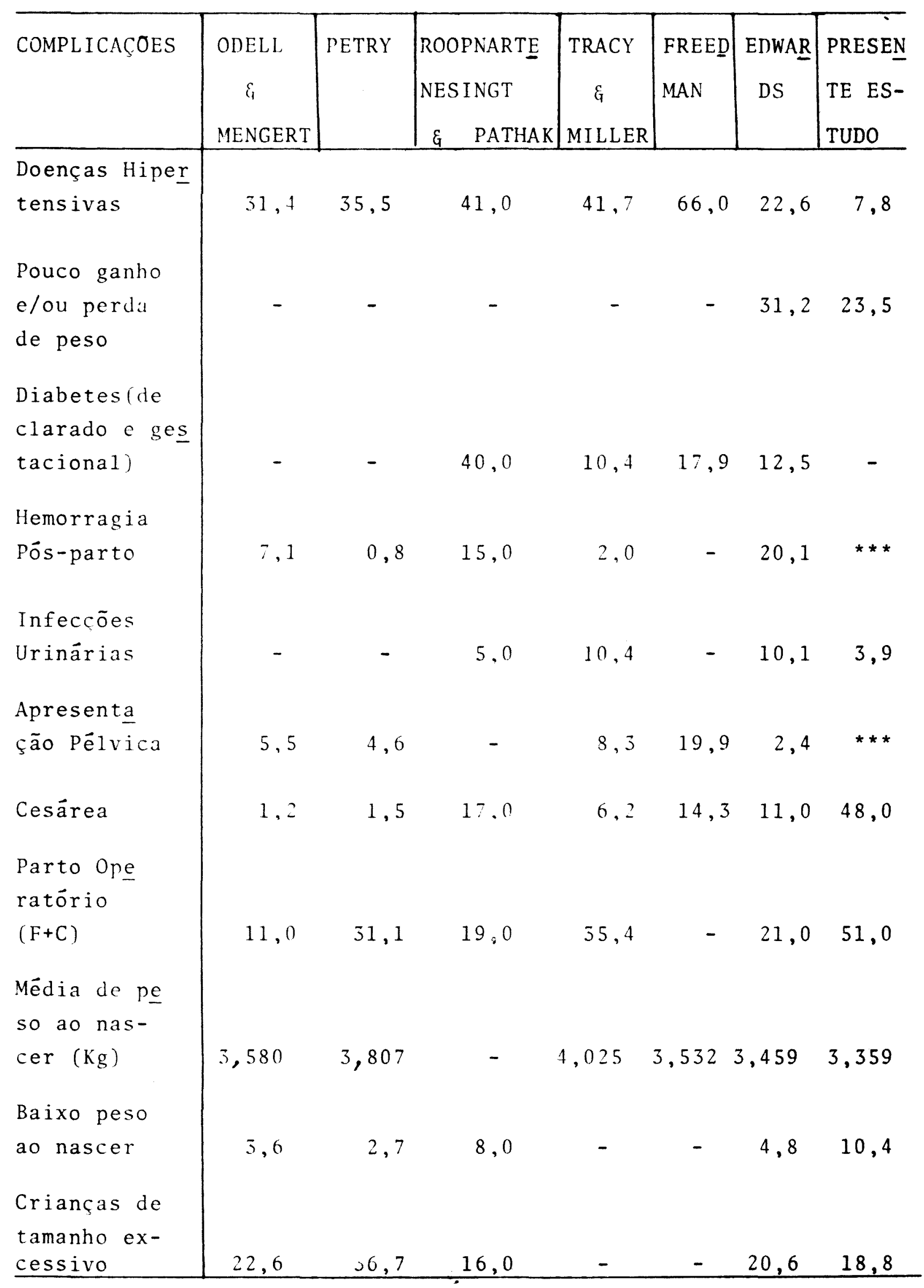

FONTE: EDWARDS, Z.E. e colaboradores 17 
Verifica-se que a incidência de doenças hipertensivas, infecçōes urinärias e diabétes é menor em ra $z$ ão do exposto anteriormente. Os dados de pouco ganho de pe so ou perda de peso, peso mëdio ao nascer e criança de tamanho excessivo se assemelham aos dos autores consultados.

A atenção ao parto é realizada em hospitais que não mantêm um sistema de informätica com o serviço de prē-natal do "Centro de Saủde Geraldo de Paula Souza" e, portanto, este serviço não dispõe de dados sobre as intercor rências ocorridas durante o período de parto e puerpério. Assim, não foi possível saber da incidência de complicações neste período, tanto no grupo das obesas como no das normais. E preciso salientar a magnitude da incidência de partos operatórios (fórceps + cesárea) no presente estudo, em decorrên cia da indiscriminação de intervenção cirürgica em nosso me - Um exemplo da falta de critério na indicação de parto cesāreo é dado por SILVEIRA ${ }^{37}$, que mostra uma incidência de $10 \%$ de cesárias em nati-mortos, no Distrito de São Paulo; es ta proporção é inadequada, uma vez que, de um modo geral, não se indica este tipo de parto para feto morto.

A inexistência de diabetes não quer dizer que não ocorreu caso de diabetes nas gestantes obesas, neste estudo, mas que o diagnóstico não foi feito em ra zão do exposto anteriormente.

\subsubsection{Idade gestaciona1}

A média de idade gestacional para o total de gestantes foi de 38 semanas e meia, sendo para as nor 
mais de 39 semanas c para as grávidas obesas de 38 . Esta diferença não é estatisticamente significantiva. A literatura menciona este mesmo fato, ou seja, não há diferenças significativas entre a idade gestacional de mulheres norma is e obesas ${ }^{32}$. E importante ressaltar que se encontrou uma incidência duas vezes maior de recém-nascidos, com menos de 37 semanas, entre as mulheres obesas. Esta foi de $8,3 \%$ nas grä vidas obesas e 3,8: nas normais. A incidoncia de recém-nascidos com 43 semanas, e mais, foi praticamente igual nos do is grupos.

\subsubsection{Ganho de peso durante a gravidez}

O ganho de peso durante a gravidez é assunto de grande controvérsia entre obstetras, nutrólogos e outros cientistas que trabalham na ārea de Saūde Materna. Autores como MAHAM ${ }^{27}$ preconizam ganho de peso de 11 a $16 \mathrm{Kg}$ para gestantes de estatura normal. Este autor ressalta, a inda, que a perda de peso, durante a gravidez, poderia levar a risco fetal em decorrēncia da queima de gordura e con sequente cetose. CORMILLOT e cols ${ }^{12}$ recomendam um ganho de peso em torno de 9 a $12 \mathrm{Kg}$ para toda e qualquer gestante, en fatizando que não é o período gestacional o melhor momento para se perder peso, mas que a gestante obesa deveria ter $\underline{u}$ ma dieta mais balanceada evitando, deste modo, ingerir hidratos de carbono e gordura em excesso; já NYIRJESY e cols 29 preconizam um ganho de peso ideal de $10 \mathrm{Kg}$ durante a gravidez. SPRYNGER e cols ${ }^{42,43}$ encontraram uma média de ganho de peso durante a gestação de $12 \mathrm{Kg}$, sendo que, na população em estu- 
do, ocorreram casos desde ingestão alimentar livre até restrição de sódio e de calorias. PECKHAM e CHRISTIANSON ${ }^{32}$ mos tram que o grupo das grảvidas obesas é o único, em seu estudo, a apresentar uma porcentagem de mulheres que tiveram ga nho de peso baixo, isto é, menos de $8 \mathrm{Kg}$, ou até mesmo uma perda de peso durante a gravidez e, portanto, foi este o gru po que teve a menor média de ganho durante a gravidez. Nesse estudo, os autores concluiram que, no grupo de mulheres obesas, quanto maior o peso pré-gestacional menor foi o ga nho de peso durante a gravidez e major o peso de recém-nascido.

No presente estudo constatou-se que o ga nho de peso das gestantes estudadas oscilou entre o mínimo de $-0,5 \mathrm{Kg}$ e o máximo de $19,5 \mathrm{~kg}$, sendo que a média de ganho de peso foi de $9,2 \mathrm{~kg}$. A tabela 9 mostra a média de ganho de peso para as gestantes normais e para as obesas. Como se pode notar, as grávidas normais têm ganho de peso médio maior que as obesas, apesar desta diferença não ser estatistica mente significante. Isto possivelmente se deve à influência da orientação alimentar dos obstetras sobre as gestantes obe sas, pois recomendam pequeno ganho de peso a este grupo.

A incidência de baixo ganho de peso $(<8$ $\mathrm{kg}$ ), ou perda de peso, observado no presente estudo, foi de 41: entre as gestantes obesas enquanto que, entre as gestan tes normais, foi de $27,7 \%$. A diferença de incidência cons tatada nos dois grupos pode ser decorrente da orientação alimentar restritiva.

Vale a pena ressaltar que nenhuma ges tante normal teve ganho de peso abaixo de $2,7 \mathrm{~kg}$ enquanto que, 
entre as obesas, houve até ganho de peso negativo $(-0,5 \mathrm{~kg})$ durante o período gravídico.

TABELA 9 - GANHO DE PESO DURANTE A GESTAÇAO DOS DOIS GRUPOS DE GESTANTES EM ESTUDO.

\begin{tabular}{l|c|c|c}
\hline GESTANTES & $N^{9}$ DE CASOS & $\begin{array}{c}\text { GANHO DE PESO } \\
\text { MEDIO }\end{array}$ & DESVIO-PADRAO \\
\hline Normais & $80^{\star}$ & 9,4 & 3,8 \\
Obesas & $50^{*}$ & 9,0 & 4,3 \\
\hline
\end{tabular}

Não hä diferença significativa a nível de 5:

* 1 caso de cada grupo com apenas 1 consulta de pré-natal.

Numa tentativa de melhor estudar a varia vel ganho de peso foi calculado o ganho de peso semanal. Alguns autores, como BRENNAN $^{8}$, consideram ganho de peso se manal excessivo aquele acima de $1 \mathrm{~kg}$ por semana.

Encontrou-se, neste estudo, um ganho de peso semanal entre 0,02 a $0,75 \mathrm{~kg}$; sendo a média de $0,43 \mathrm{Kg}$. Não houve diferença entre o ganho de peso semanal dos dois grupos de gestantes, porém, como jā foi relatado, para a média de ganho de peso durante gestação, as gestantes obe sas tiveram perda de peso ou ganho baixo ou, por vezes, au sência de ganho de peso semanal. Não foi observado nenhum caso de ganho de peso semanal excessivo, de acordo com BREN NAN $^{8}$. 


\subsubsection{Tipo de parto}

Em nosso meio, a cesārea é tão indiscriminada que torna difícil verificar a real incidência desta, relacionada a problemas obstétricos propriamente ditos. Como consta na tabela 10 a incidência de cesárea é altíssima para os dois grupos.

TABELA 10 - TIPO DE PARTO NOS DOIS GRUPOS DE GESTANTES EM ESTUDO .

\begin{tabular}{l|c|c|c|c}
\hline \multirow{2}{*}{\begin{tabular}{l|c|c} 
GESTANTES \\
DE PARTO
\end{tabular}} & \multicolumn{2}{|c}{ NORMA IS } & \multicolumn{3}{c}{ OBESAS } \\
\cline { 2 - 5 } Norma 1 & NE CASO & $\vdots$ & No DE CASO & $\vdots$ \\
Forceps & 45 & 55,6 & 25 & 49,0 \\
Cesárea & 8 & 9,8 & 3 & 5,9 \\
\hline TOTAL & 28 & 34,6 & 23 & 45,1 \\
\hline
\end{tabular}

$x^{2} o b=1,75 \quad x^{2}$ critico $=5,99$

Diferença não significativa ao nível de 5:

FISHER e FREY, ${ }^{18}$ em seu estudo, mostraram apenas $1:$ de cesāreas em gestantes obesas contra $2 \%$ nas nor mais. Já AHERN e GOODLIN ${ }^{1}$ relatam 4 casos de cesárea em pa cientes com mais de $182 \mathrm{~kg}$ e, assim mesmo, por elas apresen tarem placenta prévia, desproporção cēfalo-pēlvica (recém nascido com mais de $4500 \mathrm{~g})$, diabetes e a ủltima tendo o fe 
to em apresentação pélvica com peso de 4 200g. ODELL e MEN GERT $^{30}$ em estudo realizado apenas com gestantes obesas. constataram uma incidência de partos operatórios (Fórceps + Cesárea) de $11:$; PRETY ${ }^{33}$, MATTHEWS e DER RRUCKE ${ }^{28}$ ohservaram apenas $1,5^{\circ}$ de cesärcas em mulheres obesas. De um modo geral, a obesidade não determina um aumento de incidência de cesáreas, apesar de os recém-nascidos serem maiores e de haver uma maior incidência de complicaçōes obstētricas neste grupo.

Portanto, não se justifica a alta inci dência de cesārea nas grāvidas obesas $(45,1 \%)$ e muito menos nas normais $(34,6:)$. Assim sendo, não hä como poder avalí ar a diferença encontrada, pois a indicação de cesäreas, nos 2 grupos não foi provavelmente, decorrente de conduta obstétrica adequada.

\subsection{Estudo do recém-nascido}

Neste capitulo, foram estudados possíveis efeitos da obesidade e suas consequências sobre o feto e. o recēm-nascido.

\subsubsection{Perdas fetais}

A literatura sobre obesidade e gravidez pouco se refere às perdas fetais. Apenas se encontraram menções em MATTHEWS e DER BRUCKE ${ }^{28}$ e ODFLL e MENGERT ${ }^{30}$. que foram os primeiros a estudar o assunto, em 1938 e 1942 , respectivamente. Para os primeiros, a incidência de perda 
fetal è de 12,3: e, no segundo estudo, de 4,2\%; ambos os casos foram perdas fetais intermediārias, $\left(\begin{array}{lll}20 & \text { a } 27 \text { semanas }\end{array}\right.$ de gestação), tardias ( 28 semanas de gestação e mais) e neo natais (de 0 a 28 dias de vida). Desde 1942, até o presente momento, praticamente não se tem conhecimento de estudos de perdas fetais em grávidas obesas. Naquela época, provavel mente, as perdas fetais eram maiores que na atualidade, por falta de conhecimento técnico, e de equipamentos mais adequa dos. Como se sabe, o aprimoramento das técnicas de parto e a assistência neonatal tiveram grande avanço nos ültimos 20 anos; porém, por falta de dados mais recentes na literatura, analisaram-se os dados encontrados neste estudo, que são de 1978 , com os dos autores acima mencionados 28,30 . A incidên cia de perdas fetais (intermediárias, tardias e neonatais), em mulheres obesas, foi de $17,7 \%$, enquanto que entre mulheres normais foi de 4,9\%. Portanto, a incidência foi 3,5 vezes maior no grupo de mulheres obesas, o que parece ser $\underline{e}$ levado, como se pode observar na tabela 11.

TABELA 11 - INCIDENCIA DE PERDAS FETAIS NOS DOIS GRUPOS DE GESTANTES EM ESTUDO

\begin{tabular}{|c|c|c|c|c|}
\hline \multirow{2}{*}{ GESTANTES } & \multicolumn{2}{|c|}{ PFRDAS } & \multicolumn{2}{|c|}{ NAOO PERDAS } \\
\hline & $N:$ & $\%$ & $N^{\circ}$ & $:$ \\
\hline Norma is & 4 & 4,9 & 77 & 95,1 \\
\hline Obesas & 9 & 17,7 & 42 & 82,3 \\
\hline$x^{2}$ ob $=5,69$ & crí & $=3,84$ & & \\
\hline Diferença sig & cat & $\operatorname{ara} p$ & & \\
\hline
\end{tabular}


Esta diferença foi estatisticamente signi ficativa, o que permite afirmar que o risco de óbito fetal é maior no grupo das obesas. A comparação entre os dados da 1iteratura 28,30 com a deste estudo, mostra que incidências de perdas fetais, em gestantes obesas neste trabalho é ainda maior, o que demonstra que, apesar dos avanços tecnológ cos, outros fatores estão exercendo influência sobre esta incidência.

As causas destas perdas estão expostas, resumidamente, na tabela 12 .

TABELA 12 - CAUSA DE PERDAS FETAIS DOS DOIS GRUPOS DE GES TANTES EM ESTUDO.

\begin{tabular}{|c|c|c|}
\hline GESTANTES & OBITO FETAL & OBITO NEONATAL \\
\hline Norma is & $\begin{array}{l}\text { Perda fetal - } 1 \\
\text { (feto de } 20 \text { a } 27 \\
\text { semanas) }\end{array}$ & $\begin{array}{l}\text { broncopneumonia }-1 \\
\text { prematuridade }-2\end{array}$ \\
\hline Obesas & $\begin{array}{l}\text { Desconhecida- } 1 \\
\text { Feto inviävel- } 1 \\
\text { Perda fetal - } 3 \\
\text { (feto de } 20 \text { a } 27 \\
\text { semanas) }\end{array}$ & $\begin{array}{l}\text { Cardiopatia }-1 \\
\text { Insuficiência respi- } \\
\text { ratōria - } 1 \\
\text { Prematuridade - } 1 \\
\text { Pneumonia aspirativa } \\
\text { (1ábio leporino) - } 1\end{array}$ \\
\hline
\end{tabular}

Esta tabela mostra que as mães obesas têm um maior número de perdas fetais intermediārias e tardí w de causa desconhecida e um número mais elevado de perdas 
neonatais por malformações que as normais. CORMILLOT e cols 12 referem que existe uma maior incidencia de anomalias congênitas, de retardo mental e de desenvolvimento em filhos de grảvidas obesas.

\subsubsection{Mortalidade perinata1}

Pela incidência de perdas fetais no grupo de mulheres obesas parece importante estudar o coeficiente de mortalidade perinatal. Esta taxa è, para o total de ge tantes, de 47,6\%0 nascimentos. Ao se desdobrar nos dois grupos ela passa a $12,7 \% 0$ nascimentos para as mulheres normais e 106,4:0 nascimentos para as obesas, o que indica que a obesidade pode estar influenciando, direta ou indiretamen te, este coeficiente, mostrando, assim, uma vulnerabilidade maior a que este grupo está exposto.

Como se sabe, o periodo perinatal è aque le entre a $28 \mathrm{a}$. semana de gestação e os primeiros seis dias de vida extra-uterina; logo, influências, quer biológicas quer ambientais, atuando sobre a gestante, irão ter repercussões sobre o binômio mãe-filho.

Ao se comparar estes resultados com o de outros países, pode-se verificar que este coeficiente estā muito elevado. No Reino Unido, em $1970^{11}$ era da ordem de $22 \% 0$ e em Cuba $(1973)^{5}$ de $24,6 \%$ nascimentos. O dado deste estudo se aproxima ao de Portugal, em 1966, que era de $43,6 \% 0$ nascimentos, e é bem superior ao da Suécia que, nés ta mesma época, era de $18,9 \%$ nascimentos ${ }^{36}$. Comparando a mortalidade perinatal do grupo de gestantes obesas $(106,4 \%$ 
nascimentos) com o mesmo coeficiente para São Paulo $(42,04 \%$ nascidos vivos) ${ }^{25}$, apesar deste ter no seu denominador apenas nascidos vivos, ele é mais de duas vezes maior que o co eficiente de mortalidade perinatal para São Paulo (capita1). Isso mostra que ele está muito elevado principalmente se se levar em conta que estas gestantes são predominantemente de classe média e, portanto, deveriam ter um coeficiente mais baixo que o da capital de São Paulo como um todo. Outro fa to importante a relatar é que a incidencia de mortalidade perinatal, no grupo de obesas do estudo de PETRY 33 , foi de $3,7 \%$, inferior ao encontrado neste estudo $(10,6 \%)$. Portanto, a gestante obesa se expõe a um risco muito maior de perdas no período perinatal, apesar de receber o mesmo tipo de assistência, quer pré-natal como de parto, o que per mite concluir que, neste estudo, a obesidade $\vec{e}$ um fator de risco, que pode afetar o concepto, ou seja, a obesidade acaba sendo também um risco fetal além de materno.

\subsubsection{Peso ao nascer}

E esta, sem dúvida, a variável mais crítica do estudo e a mais estudada pelos diversos autores, pois ela parece refletir, diretamente, os agravos à saúde da mãe, ocorridos durante o período pré-gestacional, gesta cional e intergestacional.

De um modo geral, os recém-nascidos filhos de mulheres normais têm seu peso médio, ao nascer, me nor que os das obesas $17,32,33,46$. Esta diferença também foi observada no presente estudo (tabela 13); porém esta 
não è estatisticamente significativa.

TABELA 13 - MEDIA DE PESO AO NASCER DOS RECEM-NASCIDOS NOS DOIS GRUPOS DE GESTANTES EM ESTUDO.

\begin{tabular}{l|c|c|c}
\hline GESTANTES & $N^{\circ}$ DE CASOS & MEDIA DE PESO & DESVIO-PADRAO \\
\hline Normais & $80^{*}$ & 3245,9 & 552,0 \\
Obesas & $48^{* *}$ & 3359,4 & 764,7 \\
\hline
\end{tabular}

Diferenças não significativas a $5:$

* 1 Perda fetal com peso ignorado

* 3 Perdas fetais com peso ignorado

A partir deste momento, toda vez que se trabalhar com peso do recēm-nascido, ter-se-ă 128 gestantes, sendo 80 normais e 48 obesas por se terem registrado 4 perdas fetais com peso ignorado.

E interessante notar que a distribuição de peso ao nascer, é diferente entre os recém-nascidos de mulheres normais e obesas. O gráfico II ilustra bem esta diferença. TOMPKINS e WIELL ${ }^{46}$ encontram em seu trabalho uma distribuição bem semelhante à deste estudo. 
GRAFFICO II - DISTRIBUIÇAOO DE PESO,AO NASCER, DOS RECEMNASCIDOS NOS DOIS GRUPOS DE GESTANTES EM ESTU DO.

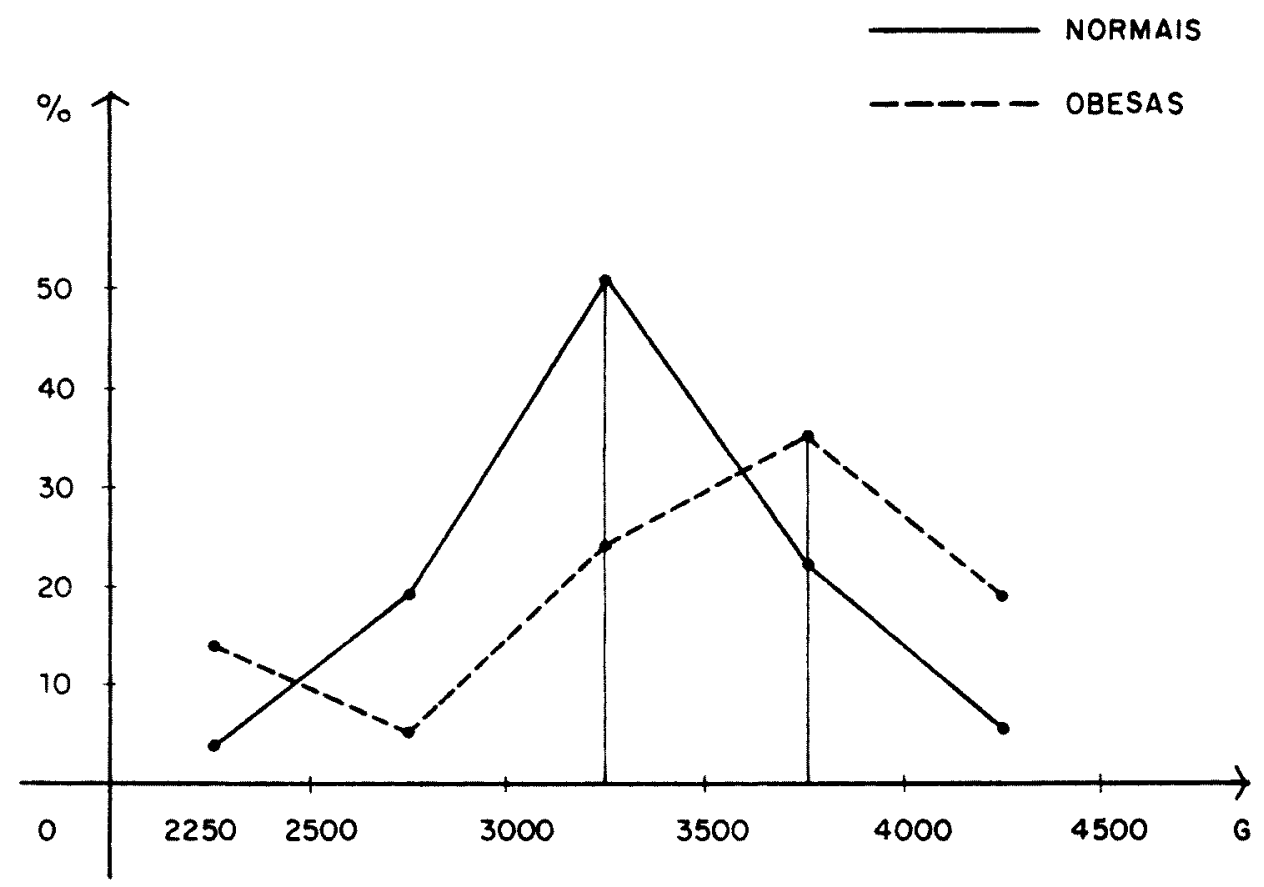

Como este gräfico mostra, as mulheres normais tem $3,8 \%$ de crianças com menos de $2.500 \mathrm{~g}$ enquanto que as obesas $10,4 \%$. Quanto às crianças de $4.000 \mathrm{~g}$ ou mais, as porcentagens foram de $5 \%$ e $18,8 \%$ nos grupos das nor mais e obesas respectivamente. Alëm de ter crianças com peso inadequado, recém-nascidos pequenos $<2.500 \mathrm{~g}$ e rran des $>4.000 \mathrm{~g}$ sendo $8,8 \%$ nas gestantes normais contra $29,2 \%$ nas obesas, tambēm hā uma inversão, ou seja, $51 \%$ de crianças com $3.000 \mathrm{~g}$ a $3.500 \mathrm{~g}$ e $22 \%$ de $3.500 \mathrm{~g}$ a $4.000 \mathrm{~g}$ nas norma is e $29 \%$ e $35 \%$ nas obesas respectivamente. As gestantes obesas tiveram poucas crianças com peso entre 2.500 a $3000 \mathrm{~g}$. 
A tabela 14 evidencia esta distribuição de peso ao nascer nos dois grupos de gestantes. Com isto, se verifica que 1 entre 3 filhos de obesas estão nascendo com peso inade quado, ou com peso inferior a $2.500 \mathrm{~g}$ ou superior a $4000 \mathrm{~g}$.

$$
\text { BATISTA, em seu estudo, mostra uma in- }
$$

cidência elevada de morbidade neonatal em fetos macrossômicos não relacionada ao diabetes materno, mas a problemas de tocotraumatismo, hipocalcemia e malformações indicando, com isto, que fetos grandes apresentam risco de adoecer muito maior que os normais.

TABELA 14 - DISTRIBUIÇAO DE PESO DOS RECEM-NASCIDOS DOS DOIS GRUPOS DE GESTANTES EM ESTUDO.

\begin{tabular}{|c|c|c|c|c|}
\hline \multirow{2}{*}{ PESO GESTANTES } & \multicolumn{2}{|c|}{ NORMAL } & \multicolumn{2}{|c|}{ OBESAS } \\
\hline & $\mathrm{N}^{\circ}$ & $\stackrel{0}{0}$ & $N^{\circ}$ & $\because$ \\
\hline$<2.500$ & 3 & 3,8 & 5 & 10,4 \\
\hline $2.500 \vdash 3.000$ & 14 & 17,5 & 3 & 6,3 \\
\hline $3.000-3.500$ & 41 & 51,2 & 14 & 29,2 \\
\hline $3.500 \vdash 4.000$ & 18 & 22,5 & 17 & 35,4 \\
\hline $4.000 \mathrm{e}+$ & $\dot{i}$ & 5,0 & 9 & 18,8 \\
\hline TOTAL & 80 & 100,0 & 48 & 100,0 \\
\hline
\end{tabular}

Como se pode notar, a distribuição de pe् so dos recém-nascidos de grávidas normais e obesas, è bem diferente. Isto se deve, talvez em uma pequena parte a fatores genéticos, como WHITELAW ${ }^{50}$ mostra em seu trabalho; 
mães obesas geram filhos com um aumento de gordura subcutânea, portanto, mais pesados; mas deve-se principalmente a fatores ambientais e comportamentais, que possam estar exer cendo influência sobre as gestantes obesas. E preciso lembrar, mais uma vez, que talvez o ganho de peso, durante a gravidez, nas obesas, que $\vec{e}$ por vezes restringido, possa es tar influindo esta distribuição.

Para descartar a possibilidade da variável paridade estar interferindo na distribuição de peso foi estabelecida uma possivel relação entre as duas variáveis (tabela 15) e pôde-se observar que não houve de fato rela ção entre elas; logo, a variāvel naridade provavelmente não está exercendo influência na distribuição do peso ao nascer. 
TABELA 15 - RELAÇAO ENTRE PESO AO NASCER E PARIDADE NOS DOIS GRUPOS DE GESTANTES EM ESTUDO.

\begin{tabular}{|c|c|c|c|c|c|c|c|c|c|c|c|c|c|c|c|c|}
\hline \multirow[b]{3}{*}{ PESO } & \multicolumn{4}{|c|}{0} & \multicolumn{4}{|c|}{1} & \multicolumn{4}{|c|}{2} & \multicolumn{4}{|c|}{$3 e+$} \\
\hline & \multicolumn{2}{|c|}{ Normais } & \multicolumn{2}{|c|}{ Obesas } & \multicolumn{2}{|c|}{ Norma is } & \multicolumn{2}{|c|}{ Obesas } & \multicolumn{2}{|c|}{ Norma is } & \multicolumn{2}{|c|}{ Obesas } & \multicolumn{2}{|c|}{ Normais } & \multicolumn{2}{|c|}{ Obesas } \\
\hline & $\mathrm{N}^{8}$ & $\stackrel{\circ}{0}$ & $N^{\circ}$ & $\frac{\circ}{b}$ & $\mathrm{~N}^{\circ}$ & $\%$ & $N^{\circ}$ & 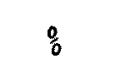 & $N^{9}$ & $\frac{\circ}{0}$ & $N^{9}$ & $\%$ & $N^{\circ}$ & $\frac{\circ}{0}$ & $N^{\circ}$ & $\%$ \\
\hline Adequado * & 18 & 72 & 9 & 69,23 & 31 & 77,5 & 12 & 66,67 & 6 & 60 & 5 & 50 & 4 & 80 & 5 & 71,43 \\
\hline İnadequado** & 7 & 28 & 4 & 30,77 & 9 & 22,5 & 6 & 33,33 & 4 & 40 & 5 & 50 & 1 & 20 & 2 & 28,57 \\
\hline TOTAL & 25 & 100 & 13 & 100 & 40 & 100 & 18 & 100 & 10 & 100 & 10 & 100 & 5 & 100 & 7 & 100 \\
\hline
\end{tabular}

$x^{2}$ ob $=3,825 \quad x^{2}$ crítico $=14,1$ Diferença não significativa

* adequado $3000 \mathrm{~g} \longmapsto 4000 \mathrm{~g}$

** inadequado $<3000 \mathrm{~g}$ e $>4000 \mathrm{~g}$ 
Outra variável, que poderia estar inflú indo nesta distribuição, é a referente a complicações obsté tricas. Porém, a única associação encontrada diz respeito ao peso ao nascer, de filho de mãe diabética; as demais não tiveram associação estatisticamente significativa com o peso ao nascer.

\subsubsection{Relação entre peso ao nascer e variáveis ma - ternas. \\ 4.2.4.1. Idade, estatura e perímetro braquial materno.}

As variáveis idade, estatura, e períme tro braquial materno parecem não estar influindo na distr $\underline{i}$ buição de peso ao nascer, dos grupos em estudo. Até mesmo a literatura é pobre em relação a estas variảveis e apenas alguns fazem menção a esta relação, como CASTILHo e cols ${ }^{10}$, que mostram não ter havido associação entre o peso do recém nascido e idade e estatura da mãe, análise esta feita pela regressão mūltipla do tipo "stepwise ". Até alguns anos atrās, pensava-se que a estatura da mãe tinha relação com o peso do recém-nascido; porēm, quando se usam tëcnicas estatisticas mais sofisticadas que possam controlar variáveis, como no caso a estatura, pode-se observar então que ela não tem associação como o peso do recém-nascido.

$$
\text { Atualmente, não se aceita mais a teoria }
$$
de associação entre estatura materna e peso do recêm-nascido. 


\subsubsection{Peso ao nascer nas gestantes anterio}

res.

Parece haver uma relação positiva entre o peso do recém-nascido da gestação anterior e o da gesta ção em estudo, pois eles parecem refletir uma histōria fami liar. Mães que tiveram filhos com peso inadequado, têm filhos com peso inadequado, e as que tiveram filhos com peso adequado geram filhos com pesos adequados. Is to ocorreu nos dois grupos de gestantes de um modo geral. Assim, das 5 gestantes obesas, que tiveram fetos acima de $4.000 \mathrm{~g}, 3$ tí nham filhos anteriores com $4000 \mathrm{~g}$ ou mais e as outras duas tiveram filhos anteriores com 3.500 a $4000 \mathrm{~g}$.

Entre as normais, das 3 que tiveram fiIhos acima de $4000 \mathrm{~g}$, uma teve um filho anterior com $4000 \mathrm{~g}$ e mais, e duas tiveram filhos entre $3000 \mathrm{~g}$ e $3500 \mathrm{~g}$.

Todas as obesas, que tiveram filhos de $2500 \mathrm{~g}$ e menos, tinham filhos anteriores com pesos entre $2500 \mathrm{~g}$ e $3000 \mathrm{~g}$. Quanto às normais, das 3 que tiveram filhos de $2500 \mathrm{~g}$ e menos, uma teve também um filho de $2500 \mathrm{~g}$ e menos; outra entre $2500 \mathrm{~g}$ e $3000 \mathrm{~g}$ e a ültima entre $3500 \mathrm{~g}$ e $4000 \mathrm{~g}$. RUSH e $\operatorname{cols}^{36}$, em estudo feito no Harlem, New York, encontra ram também esta associação entre história de filhos de baixo peso, com baixo peso, ao nascer, nas crianças da gestação a tual. Nesse estudo, é a variảvel (baixo peso ao nascer anterior) que tem a associação mais forte com o peso do recëm nascido atual. 
Portanto, além dos fatores ambientais (nutrição), parece existir um componente genético que também influi no peso do feto ao nascer.

\title{
$4 \cdot 2 \cdot 4.3$. Idade gestacional
}

\begin{abstract}
A relação entre esta variävel e o peso do recém-nascido mostrou que quase todas as crianças de menos de 37 semanas $(5,3 \%)$ apresentam peso inferior a $2500 \mathrm{~g}$ e as de 37 a 44 semanas se distribuem entre os pesos de 2500 a $4000 \mathrm{~g}$ ou mais. Hā uma exceção: 1 caso de recēm-nas cido de gestante obesa, com 41 semanas e pesando $2420 \mathrm{~g}$; po rém, era uma criança portadora de anomalia congênita grave.
\end{abstract}

A incidência de prematuridade nas gestan tes obesas foi de $8,3 \%$ enquanto que nas normais foi de $3,8 \%$, - que mostra que as obesas apresentam uma incidência 2 vezes maior de prematuridade que as grávidas normais. A literatura é escassa em relação à prematuridade em gestantes obesas. PETRY ${ }^{3 \mathfrak{3}}$, em seu estudo, encontrou uma incidência de quase 3 vezes mais prematuros em gestantes normais que nas obesas ; porém, seu critério de prematuridade era recẻm-nascido com menos de $2500 \mathrm{~g}$ e não levava em conta a idade gestacional ; logo, entre os prematuros do estudo de PETRY33, alëm dos prematuros verdadeiros, deve haver uma proporção de recēm nascidos pequenos para sua idade gestacional, o que faz com que a incidencia de prematuridade, referida por PETRY ${ }^{33}$, não 
possa ser comparada com a do presente estudo.

Pelo que se pode observar, o baixo peso que se encontrou neste estudo, entre as gestantes obesas, se deve à prematuridade e não a retardo de crescimento intra-uterino. Isto difere de gestantes normais e principal mente de desnutridas, como demonstra SIQUEIRA ${ }^{40}$ que observou o baixo peso deste $\vec{u} 1$ timo grupo se deve principalmente a retardo de crescimento intra-uterino, PIG (pequeno para idade gestacional ) e não prematuros.

\subsubsection{Tipo de parto}

Apesar de existir uma alta incidência de cesáreas tanto nas mulheres normais (35\%) como nas obesas $(48 \%)$ não existe uma relação significativa entre o tipo de parto e o peso de recém-nascido. Este fato pode ser observado na tabela 16 . 
TABELA 16 - RELAÇÃO ENTRE PESO AO NASCER E TIPO DE PARTO NOS DOIS GRUPOS DE GESTANTES EM ESTUDO •

\begin{tabular}{|c|c|c|c|c|c|c|c|}
\hline \multirow[b]{2}{*}{ PESO } & \multicolumn{3}{|c|}{ NORMAL } & \multicolumn{3}{|c|}{ OBESAS } & \multirow[t]{2}{*}{ TOTAI } \\
\hline & normal & fórceps & cesárea & normal & fórceps & cesárea & \\
\hline$<3000$ & 12 & 1 & 4 & 4 & 1 & 3 & 25 \\
\hline $3000 \vdash 4000$ & 31 & 6 & 22 & 13 & 1 & 17 & 90 \\
\hline $4000 e^{+}$ & 1 & 1 & 2 & 5 & 1 & 3 & 13 \\
\hline TOTAL & 44 & 8 & 28 & 22 & 3 & 23 & 128 \\
\hline
\end{tabular}

Como jă foi mencionado, anteriormente, a literatura refere quase a mesma incidencia de partos operatórios nas gestantes normais e obesas ${ }^{17,26}$ não sendo, por tanto, a obesidade uma causa de indicação de cesärèas, mesmo levando em conta a maior frequência com que ocorrem fe tos de grande tamanho, o que poderia resultar numa maior constância de desproporção céfalo-pélvica.

Vale ressaltar uma vez mais, que a alta incidência de cesáreas nos dois grupos, impossibilitou uma melhor análise entre o tipo de parto e o peso do recém-nas cido.

\subsubsection{Peso pré-gestacional}

Foi deixada para o fim a discussão desta 
variävel, pois parece ser a que pode trazer algumas explica çōes sobre o comportamento do peso do recẻm-nascido. Ter $\underline{\mathbf{i}}$ am os recém-nascidos, filhos de mulheres com maior peso prẹ gestacional, um peso mais alto ao nascer?

Esta indagação parece ser verdadeira. PECKHAM e CHRISTIANSON ${ }^{32}$, SIMPSON e cols 38 e WEISS \& JACK SON $^{49}$, RUSH ${ }^{35}$ entre outros relatam uma associação positiva entre o peso pré-gestacional e o peso do concepto ao nascer: quanto maior o peso prë-gestacional maior o peso do recëm nascịdo.

Esta relação também está presente neste estudo, ao se verificar que a mëdia de peso pré-gestacional das gestantes obesas é maior que as das normais (tabela 5), sendo a média de peso do recém-nascido maior nas obesas que nas normais- tabela 13. Ao detalhar o peso ao nascer pelo peso pré-gestacional, pode-se observar que, realmente, mu theres com baixo peso pré-gestacional geram filhos menores (Tabela 17) 
TABELA 17 - RELACAO ENTRE PESO PRE-GESTACIONAL E PESO AO NASCER DOS DOIS GRUPOS DE GESTANTES EM ESTUDO.

\begin{tabular}{l|c|c|c}
\hline MEDIA DE PESO & NO DE CASOS* & $\begin{array}{l}\text { MEDIA DE PESO } \\
\text { AO NASCER }\end{array}$ & $\begin{array}{c}\text { MEDIA DE GA } \\
\text { NHO DE PESO } \\
\text { SEMANAL }\end{array}$ \\
\hline $\begin{array}{l}\text { CRESO-GESTA- } \\
\text { CIONAL }\end{array}$ & 20 & $3245,5^{(1)}$ & 0,42 \\
$50 \longmapsto 60$ & 57 & $3337,9^{(2)}$ & 0,43 \\
$60 \longmapsto 70$ & 30 & $3528,0^{(3)}$ & 0,45 \\
$70+$ & 11 & 3624,6 & 0,34 \\
\hline
\end{tabular}

* 11 casos com menos de 37 semanase, 3 casos sem peso pré-ges gestacional.

Diferênça significativa ao nível de $p<0,05$ entre as médias de peso ao nascer dos itens 1 e 3,1 e 4 .

A tabela mostra ainda que o ganho de pe so semanal, quando agrupados os dois grupos (gestantes normais e obesas), e separados por faixas de peso pré-gesta cional não tem interferência sobre o peso do recém-nascido. Isso norque os extremos dos ganhos de peso excessivo, on:perda e/ou pouco ganho, estão afetando diretamente esta média. Cabe, ainda, ressaltar que, no grupo das obesas, as que tí veram um ganho de peso, durante a gravidez, inferior a $8 \mathrm{~kg}$, geram filhos menores $(3.242 \mathrm{~g})$ que as que ganharam mais de $8 \mathrm{~kg}$. Nestas $\bar{u} 1$ timas, os recēm-nascidos tiveram uma mëdia de peso de $3656 \mathrm{~g}$, o que mostra que, quando o ganho de peso, durante a gestação è inadequado, o recém-nascido tem um re 
tardo no seu crescimento intra-uterino. Portanto, uma vez mais ressalta-se que:não $\vec{e}$ o periodo de gravidez o momento mais propicio para a gestante obesa perder ou de xar de ganhar peso.

Um dos fatores de maior importância a um adequado crescimento e desenvolvimento intra-uterino do concepto é, portanto, o estado nutricional em que se encon tra a mulher antes, durante e depois do ciclo gravidico,

\subsubsection{Ganho de peso semanal}

O ganho de peso durante a gestação ê de grande importância sobre o peso do recém-nascido. Como se sabe, a perda deste, ou mesmo o pouco ganho de peso durante a gravidez, faz com que o feto tenha um retardo em seu crescimento intra-uterino e, portanto, pode apresentar com prometimento, tanto a nivel pondero-estatural como em núme ro de células, conforme o período gestacional em que o feto foi atingido. Vários estudos mostram a correlação en tre ganho de peso durante a gestação e o peso do concepto ao nascer $29,32,40$. Pode-se observar esta relação no presente estudo e verificar, tambëm, que existe uma dife rença significativa entre os pesos dos recém-nascidos das mulheres obesas com os das normais. Estes resultados cons tam da tabela 18 . 
TABELA 18 - RELAÇAO ENTRE PESO AO NASCER E GANHO DE PESO SE MANAL NOS DOIS GRUPOS DE GESTANTES EM ESTUDO •

\begin{tabular}{l|c|c|c|c}
\hline \multirow{2}{*}{$\begin{array}{l}\text { GANHO DE } \\
\text { PESO SEMANAL }\end{array}$} & \multicolumn{2}{|c|}{ NORMAIS } & \multicolumn{2}{c}{ OBESAS } \\
\cline { 2 - 5 } & No DE CASOS & $\begin{array}{c}\text { MEDIA DE PESO } \\
\text { DO RN }\end{array}$ & No DE CASOS & $\begin{array}{c}\text { MEDIA DE PESO } \\
\text { DO RN }\end{array}$ \\
\hline $0,00 \longmapsto 0,249$ & 2 & $3275 \mathrm{~g}^{(1)}$ & 5 & $3340 \mathrm{~g}^{(4)}$ \\
$0,250 \longmapsto 0,499$ & 44 & $3257 \mathrm{~g}^{(2)}$ & 22 & $3577 \mathrm{~g}^{(5)}$ \\
$0,500 \longmapsto 0,750$ & 19 & $3317 \mathrm{~g}^{(3)}$ & 10 & $3650 \mathrm{~g}^{(6)}$ \\
\hline
\end{tabular}

Houve diferença significativa ao nivel de $p<0,05$ entre as médias de peso ao nascer dos ítens 2 e 5,3 e 6 . As demais não apresentaram diferença estatístí camente significativa.

Só foram estudados, neste capítulo, os recém-nascidos de 37 semanas e mais para evitar a interferên cia do baixo peso devido à prematuridade.

Apesar de não haver diferença significa tiva entre as médias de peso ao nascer, tanto no grupo das obesas como das normais, pode-se observar que, quanto maior o ganho, maior o peso do recëm-nascido.

$$
\text { Portanto, o ganho de peso è importante }
$$
para o adequado crescimento intra-uterino. 


\subsection{Considerações gerais}

\subsubsection{Obitos maternos}

Não houve nenhum caso de óbito materno no presente estudo, isto se deve provavelmente à atenção prë-natal dedicada is gestantes, que com conduta adequada procurou reduzir o risco gravídico ao minimo. Também è preciso levar em conta que o grupo de gestantes era peque no, se comparado com a mortalidade materna que, para o nosso meio, está em torno de 9\%00 nascidos vivos. Em trabalhos como o de MAEDER e cols ${ }^{26}$, feito em Minnesota, em que se estudou uma sërie histórica de 10 anos de óbitos maternos, observou-se uma maior incidência de morte materna em obesas, sendo a principal causa o tromboembolismo e a segunda as hemorragias, principalmente pós-parto.

\subsubsection{Partos múltiplos}

De um modo geral, os autores 30,47 citam uma maior prevalência de partos múltiplos em gestantes obe sas. Como esta variável era um critério de exclusão do estudo, as gestantes que apresentaram gemelaridade não fo ram consideradas. Porém, $\vec{e}$ interessante ressaltar que o $\underline{u}$ nico caso de gemelaridade ocorreu em gestante obesa.

\subsubsection{Prevalência de obesidade na gravidez}


.57.

nas gestantes como um todo foi da ordem de $38,6 \%$. Esta prevalência está entre os valores citados por CORMILLOT e $\operatorname{cols}^{12}$ que sāo de 20 a $45 \%$. 
5. CONCLUSOES 
.58 .

1. Os resultados das tabelas 1,5 e 6 mos tram que os dois grupos de gestantes apresentam caracteristi cas diferentes entre si.

2. As grāvidas obesas apresentaram uma maior incidência de patologias, durante a gestação, que as normais, o que poderia indicar aumento do risco gravidico.

3. Os resultados aqui apresentados evidenciam o alto risco fetal a que os filhos das gestantes obe sas estão expostos-ou em relação a um elevado número de perdas fetais ou em razão da alta incidência de peso inadequado ao nascer ( $<2500 \mathrm{~g} e>4000 \mathrm{~g}$ ) o que fica evidente pelo ele vado coeficiente de mortalidade perinatal.

4. Constatou-se uma maior incidência de prematuridade no grupo das obesas que no das normais. 
5. O peso dos conceptos das gestantes normais e obesas ao nascer são diferentes e suas distribui çōes tambẻm o são, não concorrendo para tal a paridade, (que nas gestantes obesas é maior), a estatura, a idade e o perí metro braquial materno.

6. Tendo em vista o ganho de peso, durante a gravidez, existe prejuizo de crescimento fetal (me nor peso ao nascer) quando a grávida ganha menos de $8 \mathrm{Kg}$ du rante o período gestacional.

7. O peso pré-gestacional parece ser uma variảvel muito importante como meio de prognöstico de crescimento e desenvolvimento intra-uterino.

8. A prevalência de obesidade entre as gestantes è de 38,68 . 
6. REFERENCIAS BI BL IOGRAF ICAS 
REFERENCIAS BIBLIOGRAFICAS

1. AHERN,J. \& GOODLIN,R.C. Cesarian section in the massively obese. Obstet. and Gynec.. 51: 509-10, 1978 .

2. ALBRINK.M.J. Obesidad. In: BEENSON.P.B \& MCDERMOTT,W. Tratado de medicina interna de Cecil Loeb. 12a. ed. México, Ed. Interamericana, 1967, p. 1204-15.

3. ALMEIDA,P.A.M. de et al. Identificação e avaliação dos fatores clínicos da gestação de alto risco. Rev. Saú de püb1., S. Paulo, 9 : 417-25, 1975.

4. ALVARENGa,A.T. de et al. Indice de status sócio-econômico da familia da mulher grávida que frequenta o Cen tro de Saúde Geraldo de Paula Souza da Faculdade de Saưde Püblica da U.S.P. Rev. Saủde pübl., S. Paulo, 7: $351-67,1973$.

5. ALVAREZ-LAJONCHERE,C. Investigacion perinatal, Cuba, 1973. Rev. cub. Adm. Salud, 2: 269-75, 1976.

6. BATISTA,N.A. Contribuição para o estudo do recêm-nasci do de termo grande para a idade gestacional. São Pau 10, 1974. (Dissertação de mestrado-Faculdade de Med cina da U.S.P.). 
7. BRAY,G.A. et al. Evaluation of the osese patient. 1Algorithm. J.Amer. med.Ass., 235: 1487-91,1976.

8. BRENNAN, R.E. Assessment of maternal nutrition. J. Amer. diet.Ass., 75: 152-4, 1979.

9. BUTHER,N.R. \& BONHAM,D.G. Perinatal mortality: the first report of the 1958 British Perinatal Mortality Survey. Edinburgh, Livingstone, 1963.

10. CAStilho,E.A. et al. Altura materna e peso da criança ao nascer. Rev. Saüde pübl., 10: 233-7, 1976.

11. CHAMBERLAIN,R. et a1. British births 1970 . London, William Heinemann Medical Books, 1975. p 235-53.

12. CORMILlOT,A.F.J. et al. Obesidad. Buenos Aires, Ed. Med. Panamericana, 1977. p 258-64.

13. CRAIG,L. Anthropometric determinants of obesity: In: WILSON,N.L.' ed. Obesity. Philadelphia, F.A. Davis, 1969. p 13-23.

14. DELASCIO,D. \& ALMEIDA,P.A.M. de Propedêutica da gestação de alto risco . São Paulo, Livraria Manolé, 1974. p. 67 . 
15. DIDDLE,M.D. The obese obstetric and gynecologic patient. Obstet. and Gynec., $\underline{3}: 573,1954$.

16. EDITORIAL. J.Amer.med. Ass., 211: 492-3, 1970.

17. EDWARDS,L.E. et al. Pregnancy in the massively obese : course, outcome, and obesity prognosis of the infant. Amer. J. Obstet. Gynec., 131: 479-83, 1978 .

18. FISHER,J.J. \& FREY,I. Pregnancy and parturition in the obese patient. Obstet. and Gynec., 11: 92-4, 1958.

19. FRISANCHO,A.R. Triceps skin fold and upper arm muscle size norms for assessment of nutritional status. Amer. J. clin. Nutr., 27: 1052-58,1974.

20. FUNDAÇAO. IBGE. Cohsumo alimentar; antropometria, Região II: São Paulo e Região.IV: Hinas-Gerais e.Espirito Santo. Rio de Janeiro, 1977. p 96.

21. GAIN,S.M. \& CLARK,D.C. Trends in fatness and the origins of obesity. Pediatrics, 57:443-56, 1976.

22. KATZEN,H.M.\& MAHLER,R.J. Diabetes, obesity and vascular disease. Washington, D.C., Hemisphere Publishing, 1978 . p.271-80. (Advances in modern nutrition, $v .2$ ). 
23. KAWAKAMI,S. et al. N1teration of maternal bodv weight in pregnancy and postpartum. Kcio J. Med., 26: 58 $62,197 \%$.

24. KIELL,N. Introduction. In: KIELL,N., ed - The psychology of obesity. Springfield, I1? ., CHARLES C.THOMAS, 1973 p. $9-15$.

25. LAURENTi, R. et al. Mortalidade perinatal em São Paulo, Brasil. Rev. Saüde püb1., S. Paulo, 9: 115-24, 1975.

26. MAEDER,E.C. et al. Obesity: a maternal high-risk factor. Obstet. and Gynec ., 45: 669-71, 1975 .

27. MAHAN,C.S. Revolution in obstetrics: nregnancy nutrition. F1a. med. Ass., 66: $367-72,1979$.

28. MATTHEWS,H.B. \& BRUCKE; M.G. DER Normal expectancy in the extremely obese pregnant woman. J.Amer.med. Ass., 110: $554-8,1938$.

29. NYIRJESY, I. et al. Clinical significance of total weight gain in pregnancy. I-Primipara. Obstet. and Gynec., 32: $391-6,1968$.

30. ODELL,L.L.D. \& MENGERT,W.F. The overweight obstetric patient. J.Amer. med. Ass., 128: 87-90, 1945 .

31. O'DONELL,A.M. Hiponutricion y sobrealimentacion. Medicina, $38: 876-8,1978$. 
32. PECKHAM, C.II. \& CHRISTIANSON,R.E. The relationshin between prepregnancy weight and certain obste tric factors. Amer. J. Obstet. Gynec., 111: 1-7, 1971.

3.3. PETRY,J.A. Obesity with pregnancy. Obstet. and Gynec., I: 299-303, 1956 .

34. ROBSON,JR.K. Obesity : an overien. Med. Tms., 107 : $49-50,1979$.

35. RUSH, r.et a1. Antecedents of low birthweight in Hallen, New York City. Int. J. Epidem., 1: 375387,1972 .

36. SEMINARIO SOBRE LA PREVENCION DE LA MORBILIDAI Y DE LA MORTALIDAD PERINATALES, Tours, 1969. Informe • Ginebra, Organizacion Mundial de la Salud, 1972. (OMS- Cuadernos de salud publica, 42).

37. SILVEIRA,M.H. Perdas fetais do distrito de São Paulo. São Paulo, 1974. (Dissertaço de Mestrado-Faculdade de Saúde Pública da USP).

38. SIMPSON,J.W. et al. Responsability of the obstetrician to the fetus II. Influence of prepregnancy weight and pregnancy weight gain on birthweight. Obstet. and Gynec., 45: 481-87, 1975 . 
39. SIQUEIRA,A.A.F. de et al A utilização de uma curva ponderal de gestantes normais no diagnóstico da decnutricão intra-uterina. Rev. Saúde pübl., S. Pau10, 9: $195-500,1975$.

40. SIQUEIRA, A.A.F. de. Estudo de um conjunto de curvas antropométricas no diagnóstico de estado nutricional de gestantes e sua relação com o tamanho do re cém-nascido. São Paulo, 1979. (Tese de doutoramento-Faculdade de Saúde püblica da U.S.P.).

41. SPIEgel,M.R. Estatística. São Paulo, Mc Graw-Hill do Brasil, 1976 .

42. SPRINGER, I.S. et al. Nutritional indexes of clients in a maternity and infant carc project. I the target population. J.Amer. diet.Ass., 21: $013-16,1977$.

43. SPRINGER,N.S. et a1. Nutritional indexes of clients in a maternity and infant care project. I I Dietary, antropometric, and hematologic indexes of pregnant women and their infants. J.Amer. diet. Ass., 71: 617$620,1977$.

44. SPRINGER, N.S. et al. Nutritional indexes of clients in a maternity and infant care project. III Relationships between developmental, medical, and nutritional variables. J.Amer.diet.Ass., 71: 621- 23,1977. 
45. TAKAHASHI,E. Growth and enviromental factors in Japan. Hum.Biol., 38: 112-30, 1966 .

46. TOMPKINS,W.T. \& WIEHL, D.G. Effect of nutrient supplements on obese patients during pregnancy. Obstet. and Gynec., 4 : 365-73, 1954.

47. TRACY,T.A. \& MILLER,G.L. Obstetric problems of the massive1y obese. Obstet, and Gynec., 33: 204-8, 1969.

48. UDALL, J.N. et al. Interaction of maternal and neonatal obesity. Pediatrics, 62: 17-21, 1978 .

49. WEISS,W. \& JACKSON,E.L. Factores maternos que afetam el peso al nacer. In: Factores perinatales que afectam el desarrollo humano. Washington D.C., Organi zacion Panamericana de la Salud. (OPAS-Publ. cient, 185).

50. WHITELAW,G.L. Influence of maternal obesity on subcutaneous fat in the newborn. Brit. med, J., 1: 985-6, 1976.

51. WILSON,N.L. et a1. The development and perpectuation of obesity: an overview. In: WILSON,N.L., ed. Obesity. Philadelphia, F. A. Davis, 1969. p. 3-12. 